\title{
Modelling of ethanol pyrolysis in a commercial CVD reactor for growing carbon layers on alumina substrates
}

\author{
Andrey V. Minakov ${ }^{\mathrm{a}}$, Mikhail M. Simunin ${ }^{\mathrm{a}}$, Ilya I. Ryzhkov ${ }^{\mathrm{a}, \mathrm{b}, *}$ \\ ${ }^{a}$ Siberian Federal University, Svobodny 79, 660041 Krasnoyarsk, Russia \\ ${ }^{\mathrm{b}}$ Institute of Computational Modelling SB RAS, Akademgorodok 50-44, 660036 Krasnoyarsk, Russia
}

\section{A R T I C L E I N F O}

\section{Article history:}

Received 12 July 2019

Received in revised form 21 September

2019

Accepted 21 September 2019

\section{Keywords:}

Chemical vapour deposition

Ethanol pyrolysis

Chemical kinetics

Computational modelling

\begin{abstract}
A B S T R A C T
Chemical vapour deposition (CVD) is widely used for preparation of pyrolytic carbons from various precursors. The prediction of deposition kinetics requires deep understanding of all transport phenomena involved. In this work, we perform the computational modelling of ethanol pyrolysis in a commercial CVD reactor (a tube furnace). The reactor is employed for growing carbon layers on alumina substrates. The inlet gas flow is produced by evaporating azeotrope ethanol/water mixture and mixing it with inert gas (argon). The modelling is performed in 3D and 2D statements using Marinov mechanism with 57 species participating in 383 reactions. The heat and species transport is taken into account with temperature dependent physical properties. It is shown that the inlet gas velocity in the 2D statement should be corrected for a meaningful comparison with the $3 \mathrm{D}$ case. A good agreement is found between species mole fractions at the substrate position for 3D and 2D statements at low volume flow rates, while at high flow rates some deviations are observed. The temperature at the substrate position is found to be lower than at the reactor wall due to inflow of a colder gas. The main pyrolysis products at moderate temperatures (around $900{ }^{\circ} \mathrm{C}$ ) are water, ethylene, hydrogen, carbon monoxide, and methane. With increasing temperature, the mole fractions of hydrogen, acetylene, and carbon monoxide increase, while those of water and methane become smaller. With increasing ethanol/water volume flow rate, the mole fractions of ethanol and pyrolysis products saturate at some constant values due to incomplete thermal decomposition of ethanol in the reactor volume. The rise of argon flow rate leads to the decrease of pyrolysis products mole fractions due to decrease of residence time. The obtained results can be employed for simulating and analyzing pyrolysis processes in realistic CVD reactors with complex geometry as well as for the development of coupled gas phase and surface reaction model of carbon layer deposition on nanoporous substrates.
\end{abstract}

(c) 2019 Elsevier Ltd. All rights reserved.

\section{Introduction}

Chemical vapor deposition (CVD) is a process of depositing a thin solid film on a substrate through chemical reactions of gaseous species [1]. It involves the reactions in the gas phase initiated by high temperature (and possibly by radiation or plasma), and reactions, which occur at the surface leading to the formation of a solid deposit [2]. CVD is used for the formation of thin films in a wide range of applications including extraction and pyrometallurgy, materials for microelectronics and optoelectronics, protective coatings, ceramic fibers, and ceramic matrix composites [3].

\footnotetext{
* Corresponding author at: Institute of Computational Modelling SB RAS, Akademgorodok 50-44, 660036 Krasnoyarsk, Russia.

E-mail address: rii@icm.krasn.ru (I.I. Ryzhkov).
}

In carbon materials technology, pyrolytic carbon production via CVD is one of the most important processes [4]. It is widely used for preparing carbon-carbon $(\mathrm{C} / \mathrm{C})$ composites by densification of porous preforms. In the latter case, the process is often called chemical vapor infiltration (CVI). The $\mathrm{C} / \mathrm{C}$ composites find applications in aerospace industry (heat shields and aircraft brakes), medicine (protheses and implants), and nuclear technology [4,5].

Typical precursors for pyrolytic carbon formation are hydrocarbons (methane, ethylene, acetylene, propane, etc.), which are pyrolysed at high temperature $\left(900-1300^{\circ} \mathrm{C}\right.$ ) and subsequently deposit on a substrate as result of surface chemical reactions. The critical parameters controlling the deposit are the precursor gas, temperature, pressure, residence time (volume of reactor isothermal section divided by the volumetric flow rate), and ratio of surface area to free reactor volume [4]. The latter parameter determines the interaction between homogeneous and heterogeneous 


\section{Nomenclature}

$r \quad$ radial coordinate $(\mathrm{m})$

$\varphi \quad$ polar angle (rad)

$z \quad$ axial coordinate $(\mathrm{m})$

$\rho \quad$ density $\left(\mathrm{kg} / \mathrm{m}^{3}\right)$

$\mu \quad$ dynamics viscosity (Pa s)

$\kappa \quad$ thermal conductivity (W/m K)

$\alpha \quad$ heat transfer coefficient $\left(\mathrm{J} / \mathrm{m}^{2} \mathrm{~s} \mathrm{~K}\right)$

$c_{p} \quad$ specific heat capacity $(\mathrm{J} / \mathrm{kg} \mathrm{K})$

diffusion coefficient $\left(\mathrm{m}^{2} / \mathrm{s}\right)$

velocity vector $(\mathrm{m} / \mathrm{s})$

velocity magnitude $(\mathrm{m} / \mathrm{s})$

inlet axial velocity $(\mathrm{m} / \mathrm{s})$

viscous stress tensor $(\mathrm{Pa})$

unit tensor

temperature $(\mathrm{K})$

enthalpy $(\mathrm{J})$

energy source due to chemical reactions $\left(\mathrm{J} / \mathrm{m}^{3} \mathrm{~s}\right)$

heat flux $\left(\mathrm{J} / \mathrm{m}^{2} \mathrm{~s}\right)$

pressure $(\mathrm{Pa})$

operating pressure (bar)

number of species

molar mass $(\mathrm{kg} / \mathrm{mol})$

mass fraction

mole fraction

diffusive flux of species $\left(\mathrm{kg} / \mathrm{m}^{2} \mathrm{~s}\right)$

rate of production of species $k\left(\mathrm{~kg} / \mathrm{m}^{3} \mathrm{~s}\right)$

volume flow rate $\left(\mathrm{m}^{3} / \mathrm{s}\right.$ or $\left.\mathrm{ml} / \mathrm{min}\right)$

mass flow rate $(\mathrm{kg} / \mathrm{s})$

residence time $(\mathrm{s})$

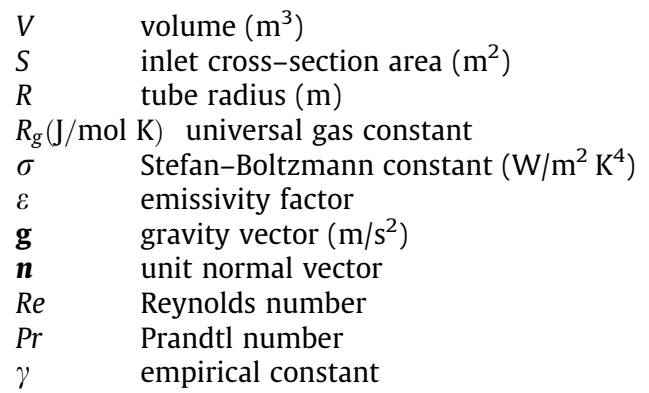

Superscripts

0 initial

Subscripts

w wall

$i \quad$ inlet

a ambient

$s \quad$ substrate

$k \quad$ species index

A argon

E ethanol

W water

EW ethanol and water

0 reference

, thermoblocks

* heated section between thermoblocks reactions as well as their relative contribution to the whole processes [6].

The prediction of deposition kinetics as well as final deposit structure requires deep understanding of all transport phenomena involved (gas phase and surface reactions, heat/mass transfer by diffusion and convection). The quantitative experimental analysis of species composition in the gas phase in CVD of carbon from the unsaturated light hydrocarbons (ethylene, acetylene, and propylene) was performed in [7]. Modelling of reaction kinetics using time-dependent homogeneous system [8] and plug-flow reactor model [9] on the basis of a scheme with 227 species and 827 reactions demonstrated a good agreement for major pyrolysis products (mole fractions larger than 0.01 ). The lumped gas-phase and surface reaction mechanisms were developed in [10] to calculate the carbon deposition from those gaseous species, which dominate CVI of pyrolytic carbon from methane. The modelling and experimental study of carbon deposition from methane was also performed in [11]. The authors used a simplified two-step reaction mechanism, but modelled the heat and mass transfer in the geometry of a cold-wall, forced-flow CVD reactor. The computed deposition rates were in good agreement with experimental results. A similar approach with simplified kinetics was used for modelling of pyrolytic carbon CVI in a multiple substrate reactor [12] as well as CVD in a vertical reactor for growing carbon nanotubes [13]. The modelling of chemical vapor deposition/infiltration in a realistic reactor geometry taking into account 28 gas-phase reactions, 4 surface reactions, and an evolving pore structure model was performed in [14].

Apart from hydrocarbons, ethanol can be considered as an attractive alternative precursor for pyrolytic carbon formation. The presence of hydroxyl group in ethanol weakens the $\mathrm{C}-\mathrm{H}$ bond, which may result in an increased reactivity in comparison with $C_{2}$ hydrocarbons [15]. The experimental studies of ethanol pyrolysis were reported in [16-18], and the major observed products were hydrogen, water, carbon monoxide, ethylene, methane, acetaldehyde, and formaldehyde. The results were compared with the detailed kinetic model of ethanol oxidation by Marinov [19], which also takes into account the kinetics of thermal ethanol decomposition. Some overestimation of experimental data by the model calculations was found at $950 \mathrm{~K} \mathrm{[17].} \mathrm{At} \mathrm{the} \mathrm{same} \mathrm{time,} \mathrm{the}$ simulations based on Marinov mechanism showed a very good agreement with the experimental results on ethanol pyrolysis in a shock tube [20]. The pyrolysis experiments in the presence of radical trappers (toluene) were performed in [18] in order to determine the rate constant of ethanol decomposition reaction into ethylene and water. The synthesis of pyrolytic carbon composites using ethanol as a precursor was reported in [15,21]. It was found that ethanol exhibits much higher deposition rate in comparison with methane. To interpret the experimental data, the pyrolysis of ethanol was modelled by two-dimensional flow model with gas-phase reaction mechanism involving 261 species participating in 1177 reactions. The decomposition of ethanol under pyrolytic conditions was studied in [22] in order to understand how the presence of ethanol affects in soot formation in fuel mixtures. It was noticed that the addition of small amounts of ethanol to acetylene inhibits the soot production [23]. Comparison between butane and ethanol pyrolysis showed that the deposit formation was much lower in the latter case [24]. The impact of mini-channel reactor geometry and heat transfer on the steam reforming of ethanol was studied in [25]. Thermodynamic analysis of ethanol steam reforming revealed that the system is highly favourable to carbon formation in the reactor volume at low residence times [26]. Detailed kinetic modelling of ethanol reforming process including pyrolysis and partial oxidation was performed in [27]. It was 
shown that ethanol features higher conversion efficiency to syngas than methane.

By using ethanol as the carbon source, a new simple catalytic CVD technique to synthesize high purity single-walled carbon nanotubes at low temperature was proposed in [28]. The high purity was attributed to the presence of hydroxyl radicals, which effectively removed the impurities, such as amorphous carbon during growth. The influence of reaction temperature on the synthesis of carbon nanotubes and nanofibers from ethanol was investigated in [29]. The systematic analysis of graphene films grown by ethanol CVD on copper foil substrates at high temperature was performed in [30]. It was noted that the interest in using ethanol lies primarily in its safety, low cost, easy handling as well as different growth kinetics due to weakly oxidizing nature. Thus, we believe that ethanol would be a promising precursor for synthesis of carbon nanotubes inside the anodic alumina membranes. The latter represent an array of aligned cylindrical nanopores with controlled diameter [31], and can be employed for chemically selective molecular transport and separation of complex molecular mixtures [32]. The ethanol CVD is also a promising technique for growing carbon layers on alumina nanofiber membranes (previously obtained using propane in $[33,34])$. The conductive carbon layer introduces new mechanisms of ion transport through nanopores due to polarization effects [35]. The ionic selectivity of such nanopores can be continuously changed from cation to anion by varying the electric potential of the conductive membrane surface [36].

Note that the prediction and control of carbon deposition kinetics on the surface of nanopores and nanofibers require extensive experimental and modelling studies. The first step in this process is the understanding of gas flow, heat transfer, and detailed gasphase kinetics in a CVD reactor with realistic geometry and boundary conditions. The optimization of flow and heat/mass transfer process in CVD reactors for improving their performance have been previously considered in a number of works [13,37-40].

In this paper, we perform 2D and 3D numerical modelling of ethanol pyrolysis in a commercial CVD reactor. The influence of temperature, pressure, ethanol, and inert gas (argon) flow rates on the gas-phase kinetics is analyzed taking into account heat and species transport in the reactor volume. This study will serve as the basis for the development of coupled gas phase and surface reaction model of carbon layer growth on nanoporous alumina substrates.

The paper is organized as follows. In Section 2, the problem statement is described, while in Section 3 the main mechanisms of ethanol pyrolysis are outlined. Comparison between 2D and 3D models is discussed in Section 4, while the influence of control parameters on the gas phase kinetics is analyzed in Sections 5-8. The main findings are summarized in Section 9.

\section{Mathematical model}

\subsection{The CVD reactor}

The chemical vapour deposition reactor consists of a cylindrical mullite tube with inlet and outlet sections made of stainless steel flanges (Fig. 1). The tube is mounted inside the electric furnace, which keeps the walls of the heated section at a given temperature $T_{w}$ by resistive heating. Two cylindrical thermoblocks made of porous alumina are used to prevent the heat loss. The substrate in the form of a thin circular disc is placed in the tube center. The mixture of ethanol, water, and inert gas (argon) is supplied through the inlet with the total volume flow rate $Q$ and temperature $T_{i}$. The gaseous mixture is prepared by the vaporization system, where the liquid mixture of ethanol and water with the volume flow rate $Q_{E W}$ and ambient temperature $T_{a}$ is evaporated and mixed with argon gas with the volume flow rate $Q_{A}$. The mass fraction of ethanol in the mixture is denoted by $\omega_{E}^{0}$. In the heated section, the ethanol is pyrolysed, and the carbon is deposited on the substrate from the pyrolysis products. The latter are removed through the outlet, which is connected to the vacuum pump. It keeps a given pressure $P$ inside the reactor by pumping out the inert gas and reaction products. The reactor is operated in the stationary regime, which is typical for flow-through tubular reactors with laminar flow $[1,2]$. This regime is established after a short transient period just after the start of mixture supply. In the stationary state, the production/consumption of species in chemical reactions is balanced by the transport of reactants and reaction products by convection and diffusion. The described system corresponds to the commercial CVD furnace OTF-1500X-UL-3 and vaporization system LVD-F1 (MTI Corp., USA), which were previously used by the authors for depositing carbon layers on nanoporous membranes [33-36]. However, the results obtained below could in principle be applied for any other tube furnace.

\subsection{Governing equations}

The stationary model of flow and gas-phase kinetics in the CVD reactor is based on the conservation laws of momentum, energy, and mass for a mixture of $N$ species. The continuity and momentum equations have the form

$\nabla \cdot(\rho \boldsymbol{u})=0$

$\nabla \cdot(\rho \boldsymbol{u} \boldsymbol{u})=-\nabla p+\nabla \cdot \Pi+\rho \mathbf{g}$

where $\rho$ is the density, $\boldsymbol{u}=\left(u_{r}, u_{\varphi}, u_{z}\right)$ is the fluid velocity, $p$ is the pressure, $\mathbf{g}$ is the gravity vector, $\Pi$ is the viscous stress tensor

$\Pi=\mu\left(\nabla \boldsymbol{u}+\nabla \boldsymbol{u}^{T}-\frac{2}{3} \nabla \cdot \boldsymbol{u} E\right)$

$\boldsymbol{u} \boldsymbol{u}, \nabla \boldsymbol{u}$ are the dyadic products, and $E$ is the unit tensor. The density is calculated assuming the ideal gas law for an incompressible fluid flow

$\rho=P\left(R_{g} T \sum_{k=1}^{N} \frac{\omega_{k}}{M_{k}}\right)^{-1}$,

where $P$ is the constant operating pressure, $R_{g}$ is the universal gas constant, $T$ is temperature, $\omega_{k}$ and $M_{k}$ are the mass fraction and molar mass of species $k$, respectively.

The energy equation is written as

$\nabla \cdot(\rho \boldsymbol{u} h)=-\nabla \cdot J_{h}+S_{h}$,

where $h$ is the enthalpy, $J_{h}=-\kappa \nabla T$ is the heat flux due to conduction, $\kappa$ is the thermal conductivity, and $S_{h}$ is the energy source due to chemical reactions (see Section 1 of Supplement Information for more details). The mixture enthalpy is calculated as

$h=\sum_{k=1}^{N} \omega_{k} h_{k}, \quad h_{k}=\int_{T_{0}}^{T} c_{p k} d T$.

Here $c_{p k}$ is the specific heat capacity of species $k$ at constant pressure and $T_{0}=298.15 \mathrm{~K}$ is the reference temperature. Note that we have neglected the thermal radiation in the energy Eq. (4). This issue will be further discussed in Section 2.5 below.

The species transport equation is given by

$\nabla \cdot\left(\rho \boldsymbol{u} \omega_{k}\right)=-\nabla \cdot J_{k}+R_{k}, \quad k=1, \ldots N$,

where $J_{k}=-\rho D_{k} \nabla \omega_{k}$ is the diffusion flux and $D_{k}$ is the diffusion coefficient of species $k$, respectively, while $R_{k}\left(\mathrm{~kg} / \mathrm{m}^{3} \mathrm{~s}\right)$ is the net rate of production of species $k$ by the chemical reactions. The expression for $R_{k}$ is given in Section 1 of Supplement Information. 


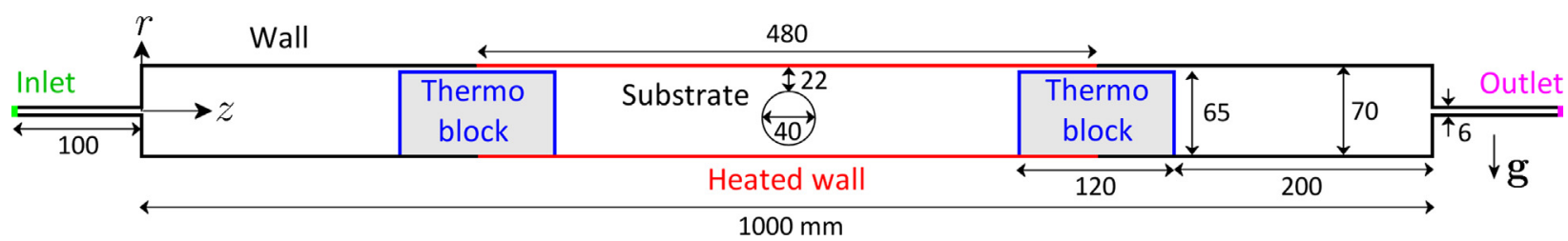

Fig. 1. The scheme of CVD reactor. All dimensions are given in $\mathrm{mm}$.

Table 1

The boundary conditions. The outward unit normal to the boundary is denoted by $\boldsymbol{n}$.

\begin{tabular}{|c|c|c|c|}
\hline Boundary segment & Momentum transfer equations & Energy transfer equation & Species transfer equations \\
\hline Inlet & $u_{r}=u_{\varphi}=0, u_{z}=U$ & $T=T_{i}$ & $\omega_{k}=\omega_{k i}$ \\
\hline Outlet & $p=P$ & $J_{h} \cdot \boldsymbol{n}=0$ & $J_{i} \cdot \boldsymbol{n}=0$ \\
\hline Wall & $\boldsymbol{u}=0$ & $J_{h} \cdot \boldsymbol{n}=\alpha\left(T-T_{a}\right)+\varepsilon \sigma\left(T^{4}-T_{a}^{4}\right)$ & $J_{i} \cdot \boldsymbol{n}=0$ \\
\hline Heated wall & $\boldsymbol{u}=0$ & $T=T_{w}$ & $J_{i} \cdot \boldsymbol{n}=0$ \\
\hline Thermoblock & $\boldsymbol{u}=0$ & $T=T^{\prime}, J_{h} \cdot \boldsymbol{n}=J_{h}^{\prime} \cdot \boldsymbol{n}$ & $J_{i} \cdot \boldsymbol{n}=0$ \\
\hline Substrate & $\boldsymbol{u}=0$ & $T=T^{\prime}, J_{h} \cdot \boldsymbol{n}=J_{h}^{\prime} \cdot \boldsymbol{n}$ & $J_{i} \cdot \boldsymbol{n}=0$ \\
\hline
\end{tabular}

Eqs. (1)-(5) are solved in the fluid zone of the reactor. Within the thermoblocks and substrate, which are made of porous alumina and characterized by the thermal conductivity $\kappa^{\prime}$, only the stationary heat transfer equation $\nabla^{2} T^{\prime}=0$ is solved.

For description of ethanol pyrolysis, we employ the chemical reaction mechanism proposed by Marinov [19], which consists of 57 species participating in 383 reactions. The mechanism is downloaded from [41] in CHEMKIN format along with the thermodynamic properties of species.

\subsection{Boundary conditions}

The boundary conditions are presented in Table 1 . The mixture is supplied into the inlet with the axial velocity $U=Q / S$ and temperature $T_{i}$, where $S$ is the inlet cross-section area. The mass fractions of ethanol $\omega_{E}$, water $\omega_{W}$, and argon $\omega_{A}$ are specified at the inlet, while the mass fractions of other components are set to zero. In the analysis below, the corresponding mole fractions $x_{E}, x_{W}, x_{A}$ will be used. At the outlet, the pressure is set to a constant value $P$, while the heat and species diffusion fluxes are set to zero since the convective transport is dominant there. On the tube and thermoblocks walls as well as on the substrate surface, the no-slip condition for velocity and the absence of species diffusion fluxes are imposed. The heated section wall is kept at constant temperature $T_{w}$, while on the other walls the Newton law of cooling with heat transfer coefficient $\alpha$ and radiative heat transfer with emissivity of wall surface denoted by $\varepsilon$ are imposed. On the walls of thermoblocks and substrate, the equality of temperatures and heat fluxes is set.

\subsection{Transient chemical kinetics model}

In this study, we also employ the chemical kinetics model at zero spatial dimension, i.e. assuming that the species mass fractions depend only on time. The species transport equation is written as

$\frac{\partial\left(\rho \omega_{k}\right)}{\partial t}=R_{k}, \quad k=1, \ldots N$.

For each considered case (see Table 2 below), the temperature and pressure are set to the given constant values $T_{w}$ and $P$, while the mass fractions corresponding to the mole fractions of ethanol $x_{E}$, water $x_{W}$, and argon $1-x_{E}-x_{W}$ are set as initial conditions. At large times, model (6) provides the values of species mass fractions at chemical equilibrium. These values will be compared with those calculated at the center of CVD reactor, where the substrate is placed.

\subsection{Physical parameters and mixture properties}

Our aim is to investigate the effect of reactor wall temperature $T_{w}$, pressure $P$, argon volume flow rate $Q_{A}$ and ethanol/water liquid mixture flow rate $Q_{E W}$ on the pyrolysis process in the gas phase. The variation of these parameters is easily accessible in a typical CVD experiment.

In the vaporization system, the liquid mixture of ethanol and water with the volume flow rate $Q_{E W}$ is mixed with argon gas with the volume flow rate $Q_{A}$ at pressure $P$ and ambient temperature $T_{a}$. After ethanol and water evaporation, the mixture is supplied to the inlet at temperature $T_{i}$. The mass flow rates of $\operatorname{argon} Q_{A}^{m}$, ethanol $Q_{E}^{m}$, and water $Q_{W}^{m}$ are calculated according to

$Q_{A}^{m}=Q_{A} \rho_{A}, \quad Q_{E}^{m}=Q_{E W} \rho_{E W} \omega_{E}^{0}, \quad Q_{W}^{m}=Q_{E W} \rho_{E W}\left(1-\omega_{E}^{0}\right)$,

where $\rho_{A}$ is the density of argon, $\rho_{E W}$ is the density of liquid ethanol/water mixture at temperature $T_{a}$ and pressure $P$, and $\omega_{E}^{0}$ is the mass fraction of ethanol. Note that the argon density can be calculated as $\rho_{A}=P M_{A} / R_{g} T_{a}$, where $M_{A}$ is the molar mass of argon. The total mass flow rate is $Q^{m}=Q_{A}^{m}+Q_{E}^{m}+Q_{W}^{m}$, while the mass fractions of components are given by

$\omega_{A}=\frac{Q_{A}^{m}}{Q^{m}}, \quad \omega_{E}=\frac{Q_{E}^{m}}{Q^{m}}, \quad \omega_{W}=\frac{Q_{W}^{m}}{Q^{m}}$.

The mole fractions are calculated as

$x_{A, E, W}=\frac{\omega_{A, E, W} / M_{A, E, W}}{\omega_{A} / M_{A}+\omega_{E} / M_{E}+\omega_{W} / M_{W}}$.

The volume flow rates at temperature $T_{i}$ and pressure $P$ are determined as follows

$Q_{A}^{\prime}=\frac{Q_{A}^{m} R_{g} T_{i}}{M_{A} P}=Q_{A} \frac{T_{i}}{T_{a}}, \quad Q_{E}^{\prime}=\frac{Q_{E}^{m} R_{g} T_{i}}{M_{E} P}, \quad Q_{W}^{\prime}=\frac{Q_{W}^{m} R_{g} T_{i}}{M_{W} P}$,

while the total volume flow rate is $Q=Q_{A}^{\prime}+Q_{E}^{\prime}+Q_{W}^{\prime}$. Here $M_{E}$ and $M_{W}$ are the molar masses of ethanol and water, respectively.

We also introduce the Reynolds number of gas flow in the tube:

$\operatorname{Re}=\frac{U 2 R \rho}{\mu}=\frac{2 Q \rho}{\pi R \mu}=\frac{2 Q^{m}}{\pi R \mu}$. 
Table 2

The list of calculated cases.

\begin{tabular}{|c|c|c|c|c|c|c|c|c|}
\hline Case & $\begin{array}{l}T_{w} \\
{ }^{\circ} \mathrm{C}\end{array}$ & $\begin{array}{c}P \\
\text { bar }\end{array}$ & $\begin{array}{c}Q_{A} \\
\mathrm{ml} / \mathrm{min}\end{array}$ & $\begin{array}{c}Q_{E W} \\
\mathrm{ml} / \mathrm{min}\end{array}$ & $\begin{array}{c}\mathrm{Q} \\
\mathrm{ml} / \mathrm{min}\end{array}$ & $x_{E}$ & $x_{W}$ & $x_{A} / x_{E}$ \\
\hline 1 & 500 & 0.5 & 2000 & 0.5 & 3446 & 0.167 & 0.020 & 4.87 \\
\hline 2 & 600 & 0.5 & 2000 & 0.5 & 3446 & 0.167 & 0.020 & 4.87 \\
\hline 3 & 700 & 0.5 & 2000 & 0.5 & 3446 & 0.167 & 0.020 & 4.87 \\
\hline 4 & 800 & 0.5 & 2000 & 0.5 & 3446 & 0.167 & 0.020 & 4.87 \\
\hline 5 & 900 & 0.5 & 2000 & 0.5 & 3446 & 0.167 & 0.020 & 4.87 \\
\hline 6 & 1000 & 0.5 & 2000 & 0.5 & 3446 & 0.167 & 0.020 & 4.87 \\
\hline 7 & 1100 & 0.5 & 2000 & 0.5 & 3446 & 0.167 & 0.020 & 4.87 \\
\hline 8 & 1200 & 0.5 & 2000 & 0.5 & 3446 & 0.167 & 0.020 & 4.87 \\
\hline 9 & 1300 & 0.5 & 2000 & 0.5 & 3446 & 0.167 & 0.020 & 4.87 \\
\hline 10 & 1400 & 0.5 & 2000 & 0.5 & 3446 & 0.167 & 0.020 & 4.87 \\
\hline 11 & 1500 & 0.5 & 2000 & 0.5 & 3446 & 0.167 & 0.020 & 4.87 \\
\hline 12 & 900 & 0.1 & 2000 & 0.5 & 6019 & 0.478 & 0.057 & 0.97 \\
\hline 13 & 900 & 0.2 & 2000 & 0.5 & 4410 & 0.326 & 0.039 & 1.95 \\
\hline 14 & 900 & 0.3 & 2000 & 0.5 & 3874 & 0.247 & 0.029 & 2.92 \\
\hline 15 & 900 & 0.4 & 2000 & 0.5 & 3606 & 0.199 & 0.024 & 3.90 \\
\hline 16 & 900 & 0.5 & 2000 & 0.5 & 3446 & 0.167 & 0.020 & 4.87 \\
\hline 17 & 900 & 0.6 & 2000 & 0.5 & 3339 & 0.144 & 0.017 & 5.85 \\
\hline 18 & 900 & 0.8 & 2000 & 0.5 & 3205 & 0.112 & 0.013 & 7.80 \\
\hline 19 & 900 & 1 & 2000 & 0.5 & 3125 & 0.092 & 0.011 & 9.75 \\
\hline 20 & 900 & 0.5 & 10 & 0.5 & 657 & 0.875 & 0.104 & 0.02 \\
\hline 21 & 900 & 0.5 & 200 & 0.5 & 924 & 0.623 & 0.074 & 0.49 \\
\hline 22 & 900 & 0.5 & 400 & 0.5 & 1204 & 0.478 & 0.057 & 0.97 \\
\hline 23 & 900 & 0.5 & 600 & 0.5 & 1484 & 0.388 & 0.046 & 1.46 \\
\hline 24 & 900 & 0.5 & 800 & 0.5 & 1764 & 0.326 & 0.039 & 1.95 \\
\hline 25 & 900 & 0.5 & 1000 & 0.5 & 2045 & 0.281 & 0.033 & 2.44 \\
\hline 26 & 900 & 0.5 & 1200 & 0.5 & 2325 & 0.247 & 0.029 & 2.92 \\
\hline 27 & 900 & 0.5 & 1400 & 0.5 & 2605 & 0.221 & 0.026 & 3.41 \\
\hline 28 & 900 & 0.5 & 1600 & 0.5 & 2885 & 0.199 & 0.024 & 3.90 \\
\hline 29 & 900 & 0.5 & 1800 & 0.5 & 3165 & 0.182 & 0.022 & 4.38 \\
\hline 30 & 900 & 0.5 & 2000 & 0.5 & 3446 & 0.167 & 0.020 & 4.87 \\
\hline 31 & 900 & 0.5 & 2000 & 0.05 & 2867 & 0.020 & 0.002 & 48.71 \\
\hline 32 & 900 & 0.5 & 2000 & 0.25 & 3124 & 0.092 & 0.011 & 9.74 \\
\hline 33 & 900 & 0.5 & 2000 & 0.5 & 3446 & 0.167 & 0.020 & 4.87 \\
\hline 34 & 900 & 0.5 & 2000 & 1 & 4089 & 0.281 & 0.033 & 2.44 \\
\hline 35 & 900 & 0.5 & 2000 & 2 & 5376 & 0.428 & 0.051 & 1.22 \\
\hline 36 & 900 & 0.5 & 2000 & 3 & 6663 & 0.518 & 0.061 & 0.81 \\
\hline 37 & 900 & 0.5 & 2000 & 4 & 7950 & 0.579 & 0.069 & 0.61 \\
\hline 38 & 900 & 0.5 & 2000 & 5 & 9237 & 0.623 & 0.074 & 0.49 \\
\hline
\end{tabular}

Here $R$ is the tube radius, $Q=U \pi R^{2}$ is the total volume flow rate, $Q^{m}=Q \rho$ is the total mass flow rate, $\rho$ and $\mu$ are the density and dynamic viscosity of gas mixture, respectively. Note that $R$ varies from $3 \mathrm{~mm}$ at the inlet to $35 \mathrm{~mm}$ in the central heated section, see Fig. 1. In addition, there are spaces above thermoblocks with the maximum gap of $2.5 \mathrm{~mm}$.

The list of calculated cases is presented in Table 2. The ambient temperature is $T_{a}=25{ }^{\circ} \mathrm{C}$, while the inlet temperature is set to $T_{i}=150{ }^{\circ} \mathrm{C}$ since the mixture is heated in the vaporization system. The other parameters are as follows: $\rho_{E W}=798.64 \mathrm{~kg} / \mathrm{m}^{3}$, $M_{A}=39.95 \mathrm{~g} / \mathrm{mol}, M_{E}=46.07 \mathrm{~g} / \mathrm{mol}, M_{W}=18.02 \mathrm{~g} / \mathrm{mol}[42,43]$. The ethanol mass fraction $\omega_{E}^{0}=0.9557$ corresponds to the azeotrope mixture. Since in most cases in Table 2 the ratio of argon to ethanol mole fraction $x_{A} / x_{E}>1$ (except cases 12, 20-22, 3638 ), the viscosity and thermal conductivity of the mixture are taken equal to those of argon. The corresponding temperature dependencies are plotted in the Supplement Information (Fig. S4).

Let us estimate the Reynolds number of flow at the tube inlet ( $R=3 \mathrm{~mm}$ ) using formula (9) and putting $\mu=2.99 \cdot 10^{-5} \mathrm{~Pa} \mathrm{~s}$, which is the viscosity of argon at the inlet temperature of $150{ }^{\circ} \mathrm{C}$ [43]. The variation of wall temperature (Cases 1-11 in Table 2) does not affect the Reynolds number at the inlet $(\operatorname{Re}=238)$. The variation of pressure (Cases 12-19) results in the change of Re from 85 to 429, while the argon volume flow rate variation (Cases $20-30$ ) leads to the change of $R e$ from 48 to 238. Finally, the increase of ethanol/water mixture liquid flow rate (Cases 31-38) increases $R e$ from 195 to 663 . The use of ethanol vapor viscosity instead of argon viscosity in formula (9) provides the Re values, which are 2.4 times higher than the above-mentioned ones. However, they do not exceed the value of $R e=2300$, where the transition to turbulence starts. Note that in the heated section, the Reynolds number (9) greatly reduces in comparison with the inlet value due to the increase of viscosity (Fig. S4) and the expansion of tube radius (at the same time, the mass flow rate $Q^{m}$ does not change along the tube). The presented considerations fully justify the assumption of laminar flow in the reactor.

The preliminary calculations of ethanol pyrolysis in the working range of parameters showed that 14 species mainly contribute to the stationary mixture composition in the reactor: $\mathrm{H}_{2}, \mathrm{CO}, \mathrm{CO}_{2}$, $\mathrm{H}_{2} \mathrm{O}, \mathrm{CH}_{4}, \mathrm{C}_{2} \mathrm{H}_{2}, \mathrm{C}_{2} \mathrm{H}_{4}, \mathrm{C}_{2} \mathrm{H}_{6}, \mathrm{C}_{3} \mathrm{H}_{6}, \mathrm{C}_{3} \mathrm{H}_{8}, \mathrm{CH}_{3} \mathrm{CHO}, \mathrm{CH}_{2} \mathrm{O}, \mathrm{C}_{2} \mathrm{H}_{5} \mathrm{OH}$, Ar. The mole fractions of other species are negligibly small and cannot affect the mixture physical properties. We have calculated the dependence of binary diffusion coefficients for 13 selected species in argon on temperature on the basis of kinetic theory in the range $273.15-1800 \mathrm{~K}$ and found good agreement with the experimental data. The obtained values were approximated by quadratic polynomials of temperature. The dependence of diffusion coefficients on pressure was taken into account according to kinetic theory

$D_{k}(T, P)=D_{k}\left(T, P_{0}\right) \frac{P_{0}}{P}$,

where $P_{0}$ is the reference pressure of 1 bar. The diffusion coefficients $D_{k}\left(T, P_{0}\right)$ are plotted as functions of temperature in the Supplement Information (Fig. S5). 
The porous alumina thermoblocks and substrate have the following physical properties: bulk density $1561 \mathrm{~kg} / \mathrm{m}^{3}$, specific heat capacity $1260 \mathrm{~J} / \mathrm{kg} \mathrm{K}$, and thermal conductivity $2 \mathrm{~W} / \mathrm{m} \mathrm{K}$. These data are estimated on the basis of pure alumina and argon properties at $1000{ }^{\circ} \mathrm{C}[42,44]$ taking into account the thermoblocks porosity of 0.6 . The estimated value of thermal conductivity agrees well with the literature data [45]. The heat transfer coefficient in the boundary condition of the tube wall is taken as $5 \mathrm{~W} / \mathrm{m}^{2} \mathrm{~K}$ [44], while its emissivity is set to 0.45 [46]. The substrate diameter is $40 \mathrm{~mm}$ and the thickness is $0.4 \mathrm{~mm}$, see [33,34] for more details.

Note that we have neglected the heat transfer by thermal radiation in the reactor volume, see energy Eq. (4). It is taken into account in the boundary conditions only, see Table 1. First of all, the dominant species in the gas phase is argon, which is transparent for thermal radiation. Second, the furnace is normally operated at low pressure (0.1-0.5 bar). For such pressures, the adsorption coefficients of other gases (ethanol, water, carbon monoxide, etc.) are low. Third, the temperature in the heated section is almost homogeneous at the stationary state. Under such conditions, the absorption of thermal radiation in the reactor volume can be neglected for the stationary problem. However, it could be important for the transient problem, where the thermal radiation could affect the heating rate of gas in the tube.

On the basis of calculations, we will analyze the following parameters: temperature $T_{s}$ and species mole fractions averaged over the substrate surface, temperature $\bar{T}$ and species mole fractions averaged over the radial cross-section of the tube (the latter quantities are functions of $z$ coordinate). An important parameter is the residence time, which is defined by

$\tau=V_{*} / Q_{*}$,

where $V_{*}$ is the volume of the heated section between thermoblocks (see Fig. 1) and $Q_{*}=U_{*} S_{*}$ is the volume flow rate with $U_{*}$ being the axial velocity averaged over volume $V_{*}$ and $S_{*}$ being the area of tube radial cross-section.

\subsection{Numerical implementation}

We have performed the modelling of CVD reactor in three-dimensional (3D) and two-dimensional (2D) statements. The solution of $3 \mathrm{D}$ problem requires high computational cost and is not suitable for parametric studies. Thus, a series of 3D calculations was performed in order to choose and justify a proper reduction of full 3D problem to 2D problem. The latter was further used for studying the system response to the variation of control parameters.

The 3D modelling is performed using cylindrical coordinates $(r, \varphi, z)$. The governing equations are solved in half of the tube $0 \leqslant \varphi<\pi$, where the value $\varphi=0$ corresponds to the $r$ axis shown in Fig. 1. The gravity vector is written as $\mathbf{g}=(\mathrm{g}, \pi, 0)$, where $\mathrm{g}=9.81 \mathrm{~m} / \mathrm{s}^{2}$. The symmetry boundary conditions are imposed on the plane $\varphi=0, \pi$. In the case of $2 \mathrm{D}$ modelling, the equations are solved on the $(r, z)$ plane using Cartesian coordinates. This plane corresponds to the vertical longitudinal cross-section of the tube. In this case, $\mathbf{g}=(-\mathrm{g}, 0)$.

As a result of 3D modelling, the corrected values of gas velocity, which should be imposed at the inlet of 2D problem, have been determined. The correction is required in order to obtain $2 \mathrm{D}$ velocity and temperature fields, which closely resemble their 3D counterparts taken at the vertical longitudinal cross-section of the tube. The inlet velocity for 2D problem is calculated as $U^{\prime}=\gamma U$, where $\gamma=0.1096$ is the empirical coefficient determined from the series of calculations. It provides close agreement between axial velocity profiles in 2D geometry and in the corresponding plane of $3 \mathrm{D}$ geometry in the heated section of the tube, where the substrate is located. Note that the substrate was not considered in the 2D problem statement due to its geometry of a thin circular disc.

The simulations are performed in the software package ANSYS Fluent 17 using the finite-volume method on structured grids. The 2D grid is composed of 61300 cells, while the 3D grid consists of 822000 cells, see Figs. S1-S3 in the Supplement Information. The clustering is introduced near the inlet and outlet nozzles as well as in the gap between tube wall and thermoblocks. Mesh sensitivity analysis is presented in the Supplement Information (Table S1). The coupling of velocity and pressure fields for incompressible flow is ensured using the SIMPLE-C procedure. In this case, the resulting scheme becomes conservative automatically. The approximation of convective terms in the transport equations is carried out by means of second-order upwind scheme. Diffusion flows and source terms are approximated by finite-volume analogues of central-difference relations with the second order of accuracy. For solving chemical kinetics equations, the built-in solver for stiff systems of ordinary differential equations was used. Full convergence of the iteration process was achieved on average over 50000 iterations. Convergence control was carried out by monitoring the behavior of average values of the main 14 components in the tube furnace.

The equations of transient chemical kinetics model (6) are also solved using ANSYS Fluent 17. Note that this package does not allow solving problems with zero or one spatial dimension. Thus, a small 2D domain of $10 \mathrm{~mm} \times 10 \mathrm{~mm}$ covered by $10 \times 10$ mesh is employed with boundary condition of zero species fluxes. The species mass fractions are time-dependent and spatially uniform, while the velocity is set to zero, and temperature and pressure are set to constant values.

\section{The mechanism of ethanol pyrolysis}

In this section, we provide an overview of ethanol thermal decomposition mechanisms and outline the main reaction paths. The description is based on the literature data $[15,16,19-21,27]$ as well as on the analysis of kinetic reaction rates for the considered configuration. They determine the contribution of each reaction to the production of a given species. The reaction rates are calculated at the entrance to the heated section of the reactor (a thin gap above the left thermoblock on Fig. 1), where they typically reach maximum by absolute value.

The unimolecular decomposition of ethanol occurs via the following reactions

$$
\begin{aligned}
& \mathrm{C}_{2} \mathrm{H}_{5} \mathrm{OH}+\mathrm{M}=\mathrm{C}_{2} \mathrm{H}_{4}+\mathrm{H}_{2} \mathrm{O}+\mathrm{M}, \\
& \mathrm{C}_{2} \mathrm{H}_{5} \mathrm{OH}+\mathrm{M}=\mathrm{CH}_{3}+\mathrm{CH}_{2} \mathrm{OH}+\mathrm{M}, \\
& \mathrm{C}_{2} \mathrm{H}_{5} \mathrm{OH}+\mathrm{M}=\mathrm{C}_{2} \mathrm{H}_{5}+\mathrm{OH}+\mathrm{M}, \\
& \mathrm{C}_{2} \mathrm{H}_{5} \mathrm{OH}+\mathrm{M}=\mathrm{CH}_{3} \mathrm{CHO}+\mathrm{H}_{2}+\mathrm{M} .
\end{aligned}
$$

Here ' $M$ ' corresponds to the third-bodies, i.e. collision partners, which supply or carry away the energy in the reaction. The reaction (R1) is dominant over a wide range of conditions $(P<10$ bar, $T=700-2500 \mathrm{~K}$ ) [47]. It has the lowest threshold energy followed by reactions (R2), (R3), and (R4). The last three reactions correspond to the breaking of $\mathrm{C}-\mathrm{C}, \mathrm{C}-\mathrm{O}, \mathrm{C}-\mathrm{H}$ and $\mathrm{O}-\mathrm{H}$ bonds, respectively, in the ethanol molecule.

Further decomposition of ethanol takes place via abstraction reactions leading the formation of isomeric radicals, namely $\mathrm{C}_{2} \mathrm{H}_{4} \mathrm{OH}$ (2-hydroxyethyl radical), $\mathrm{CH}_{3} \mathrm{CHOH}$ (1-hydroxyethyl radical), and $\mathrm{CH}_{3} \mathrm{CH}_{2} \mathrm{O}$ (ethoxy radical). The attack of ethanol by the methyl radical results in the production of methane via reactions 


$$
\begin{aligned}
& \mathrm{C}_{2} \mathrm{H}_{5} \mathrm{OH}+\mathrm{CH}_{3}=\mathrm{C}_{2} \mathrm{H}_{4} \mathrm{OH}+\mathrm{CH}_{4}, \\
& \mathrm{C}_{2} \mathrm{H}_{5} \mathrm{OH}+\mathrm{CH}_{3}=\mathrm{CH}_{3} \mathrm{CHOH}+\mathrm{CH}_{4}, \\
& \mathrm{C}_{2} \mathrm{H}_{5} \mathrm{OH}+\mathrm{CH}_{3}=\mathrm{CH}_{3} \mathrm{CH}_{2} \mathrm{O}+\mathrm{CH}_{4} .
\end{aligned}
$$

The hydrogen abstraction reactions with $\mathrm{OH}$ produce the same isomeric radicals and water

$$
\begin{aligned}
& \mathrm{C}_{2} \mathrm{H}_{5} \mathrm{OH}+\mathrm{OH}=\mathrm{C}_{2} \mathrm{H}_{4} \mathrm{OH}+\mathrm{H}_{2} \mathrm{O}, \\
& \mathrm{C}_{2} \mathrm{H}_{5} \mathrm{OH}+\mathrm{OH}=\mathrm{CH}_{3} \mathrm{CHOH}+\mathrm{H}_{2} \mathrm{O}, \\
& \mathrm{C}_{2} \mathrm{H}_{5} \mathrm{OH}+\mathrm{OH}=\mathrm{CH}_{3} \mathrm{CH}_{2} \mathrm{O}+\mathrm{H}_{2} \mathrm{O},
\end{aligned}
$$

while the interaction with $\mathrm{H}$ radical leads to the formation of molecular hydrogen:

$$
\begin{aligned}
& \mathrm{C}_{2} \mathrm{H}_{5} \mathrm{OH}+\mathrm{H}=\mathrm{C}_{2} \mathrm{H}_{4} \mathrm{OH}+\mathrm{H}_{2}, \\
& \mathrm{C}_{2} \mathrm{H}_{5} \mathrm{OH}+\mathrm{H}=\mathrm{CH}_{3} \mathrm{CHOH}+\mathrm{H}_{2}, \\
& \mathrm{C}_{2} \mathrm{H}_{5} \mathrm{OH}+\mathrm{H}=\mathrm{CH}_{3} \mathrm{CH}_{2} \mathrm{O}+\mathrm{H}_{2} .
\end{aligned}
$$

The 2-hydroxyethyl radical decomposes to produce ethylene via reaction

$$
\mathrm{C}_{2} \mathrm{H}_{4} \mathrm{OH}=\mathrm{C}_{2} \mathrm{H}_{4}+\mathrm{OH} \text {. }
$$

The other ethanol radicals are consumed to form acetaldehyde

$$
\mathrm{CH}_{3} \mathrm{CHOH}+\mathrm{M}=\mathrm{CH}_{3} \mathrm{CHO}+\mathrm{H}+\mathrm{M} \text {, }
$$

$\mathrm{CH}_{3} \mathrm{CH}_{2} \mathrm{O}+\mathrm{M}=\mathrm{CH}_{3} \mathrm{CHO}+\mathrm{H}+\mathrm{M}$

and formaldehyde

$\mathrm{CH}_{3} \mathrm{CH}_{2} \mathrm{O}+\mathrm{M}=\mathrm{CH}_{3}+\mathrm{CH}_{2} \mathrm{O}+\mathrm{M}$,

$\mathrm{CH}_{2} \mathrm{OH}+\mathrm{M}=\mathrm{CH}_{2} \mathrm{O}+\mathrm{H}+\mathrm{M}$.

The decomposition of formaldehyde occurs via the reactions

$\mathrm{CH}_{2} \mathrm{O}+\mathrm{H}=\mathrm{HCO}+\mathrm{H}_{2}$,

$\mathrm{CH}_{2} \mathrm{O}+\mathrm{OH}=\mathrm{HCO}+\mathrm{H}_{2} \mathrm{O}$.

The formyl radical is consumed to form carbon monoxide

$\mathrm{HCO}+\mathrm{M}=\mathrm{H}+\mathrm{CO}+\mathrm{M}$.

The attack of methyl and hydrogen radicals on acetaldehyde produces the acetyl radical as well as methane and hydrogen, respectively:

$\mathrm{CH}_{3} \mathrm{CHO}+\mathrm{CH}_{3}=\mathrm{CH}_{3} \mathrm{CO}+\mathrm{CH}_{4}$,

$\mathrm{CH}_{3} \mathrm{CHO}+\mathrm{H}=\mathrm{CH}_{3} \mathrm{CO}+\mathrm{H}_{2}$.

The further decomposition leads to carbon monoxide formation

$\mathrm{CH}_{3} \mathrm{CO}+\mathrm{M}=\mathrm{CH}_{3}+\mathrm{CO}+\mathrm{M}$.

The decomposition of acetaldehyde also occurs via the following paths, where vinoxy radical is formed:

$\mathrm{CH}_{3} \mathrm{CHO}+\mathrm{H}=\mathrm{CH}_{2} \mathrm{CHO}+\mathrm{H}_{2}$,

$\mathrm{CH}_{3} \mathrm{CHO}+\mathrm{OH}=\mathrm{CH}_{2} \mathrm{CHO}+\mathrm{H}_{2} \mathrm{O}$,

$\mathrm{CH}_{3} \mathrm{CHO}+\mathrm{CH}_{3}=\mathrm{CH}_{2} \mathrm{CHO}+\mathrm{CH}_{4}$.

This radical is further decomposed into ketene and hydrogen radical

$\mathrm{CH}_{2} \mathrm{CHO}=\mathrm{CH}_{2} \mathrm{CO}+\mathrm{H}$

followed by the evolution of carbon monoxide

$\mathrm{CH}_{2} \mathrm{CO}+\mathrm{H}=\mathrm{CH}_{3}+\mathrm{CO}$.

There attack of $\mathrm{OH}$ radical on acetaldehyde also leads to the formation of formic acid

$\mathrm{CH}_{3} \mathrm{CHO}+\mathrm{OH}=\mathrm{CH}_{3}+\mathrm{HCOOH}$.

The carbon dioxide is mainly produced via the following reaction paths

$$
\begin{aligned}
& \mathrm{CO}+\mathrm{OH}=\mathrm{CO}_{2}+\mathrm{H}, \\
& \mathrm{CH}_{3} \mathrm{CH}_{2} \mathrm{O}+\mathrm{CO}=\mathrm{C}_{2} \mathrm{H}_{5}+\mathrm{CO}_{2}, \\
& \mathrm{HCOOH}+\mathrm{H}=\mathrm{CO}_{2}+\mathrm{H}_{2}+\mathrm{H}, \\
& \mathrm{HCOOH}+\mathrm{OH}=\mathrm{CO}_{2}+\mathrm{H}_{2} \mathrm{O}+\mathrm{H} .
\end{aligned}
$$

The ethylene obtained in reactions (R1) and (R14) is decomposed in the unimolecular reaction

$\mathrm{C}_{2} \mathrm{H}_{4}+\mathrm{M}=\mathrm{C}_{2} \mathrm{H}_{2}+\mathrm{H}_{2}+\mathrm{M}$

as well as in the following reactions with methyl, hydroxyl, and hydrogen radicals:

$\mathrm{C}_{2} \mathrm{H}_{4}+\mathrm{CH}_{3}=\mathrm{C}_{2} \mathrm{H}_{3}+\mathrm{CH}_{4}$

$\mathrm{C}_{2} \mathrm{H}_{4}+\mathrm{OH}=\mathrm{C}_{2} \mathrm{H}_{3}+\mathrm{H}_{2} \mathrm{O}$,

$\mathrm{C}_{2} \mathrm{H}_{4}+\mathrm{H}=\mathrm{C}_{2} \mathrm{H}_{3}+\mathrm{H}_{2}$

In addition, the ethyl radical is formed in the reaction

$\mathrm{C}_{2} \mathrm{H}_{4}+\mathrm{H}+\mathrm{M}=\mathrm{C}_{2} \mathrm{H}_{5}+\mathrm{M}$.

The vinyl radical $\mathrm{C}_{2} \mathrm{H}_{3}$ is consumed to the production of acetylene:

$\mathrm{C}_{2} \mathrm{H}_{3}=\mathrm{C}_{2} \mathrm{H}_{2}+\mathrm{H}$,

$\mathrm{C}_{2} \mathrm{H}_{3}+\mathrm{CH}_{3}=\mathrm{C}_{2} \mathrm{H}_{2}+\mathrm{CH}_{4}$

$\mathrm{C}_{2} \mathrm{H}_{3}+\mathrm{H}=\mathrm{C}_{2} \mathrm{H}_{2}+\mathrm{H}_{2}$.

Reactions (R22), (R27), (R36), and (R41) provide additional sources of methane.

The methyl radical recombination reaction and ethyl radical interaction with hydrogen radical produce ethane

$\mathrm{CH}_{3}+\mathrm{CH}_{3}+\mathrm{M}=\mathrm{C}_{2} \mathrm{H}_{6}+\mathrm{M}$,

$\mathrm{C}_{2} \mathrm{H}_{5}+\mathrm{H}=\mathrm{C}_{2} \mathrm{H}_{6}$.

The propylene is formed via reactions of vynil and 1-hydroxyethyl radicals with the methyl radical

$\mathrm{C}_{2} \mathrm{H}_{3}+\mathrm{CH}_{3}=\mathrm{C}_{3} \mathrm{H}_{6}$

$\mathrm{CH}_{3} \mathrm{CHOH}+\mathrm{CH}_{3}=\mathrm{C}_{3} \mathrm{H}_{6}+\mathrm{H}_{2} \mathrm{O}$.

The interaction of ethyl and methyl radicals leads to the formation of propane

$\mathrm{C}_{2} \mathrm{H}_{5}+\mathrm{CH}_{3}=\mathrm{C}_{3} \mathrm{H}_{8}$.

The contributions of the described reactions paths to the decomposition of ethanol essentially depend on temperature. We will discuss it in more details in Section 5, where the calculated profiles of species along the reactor as well as the dependence of their concentration on temperature will be presented.

\section{Comparison between 2D and 3D models}

Let us start the discussion of results with the comparison between 2D and 3D models. The velocity and temperature fields obtained from 3D calculations are presented in Fig. 2. The mole fractions fields for selected species can be found in the Supplement Info (Fig. S6). The comparison of temperature fields between the models is shown in Fig. 3. For 3D model, the vertical cross-section $\phi=0, \pi$ is shown, and one can see that the $2 \mathrm{D}$ model provides similar results. The temperature in the heated section between thermoblocks is rather uniform. Strong temperature gradients are observed inside thermoblocks and near their faces, which are in contact with inlet and outlet sections of the tube (i.e. the volume between inlet and left thermoblock and the volume between right thermoblock and outlet, respectively).

The velocity magnitude field $u=|\boldsymbol{u}|$ is presented in Fig. 4 . Although there are some differences between velocity fields in the inlet and outlet sections for $2 \mathrm{D}$ and $3 \mathrm{D}$ models, their. 


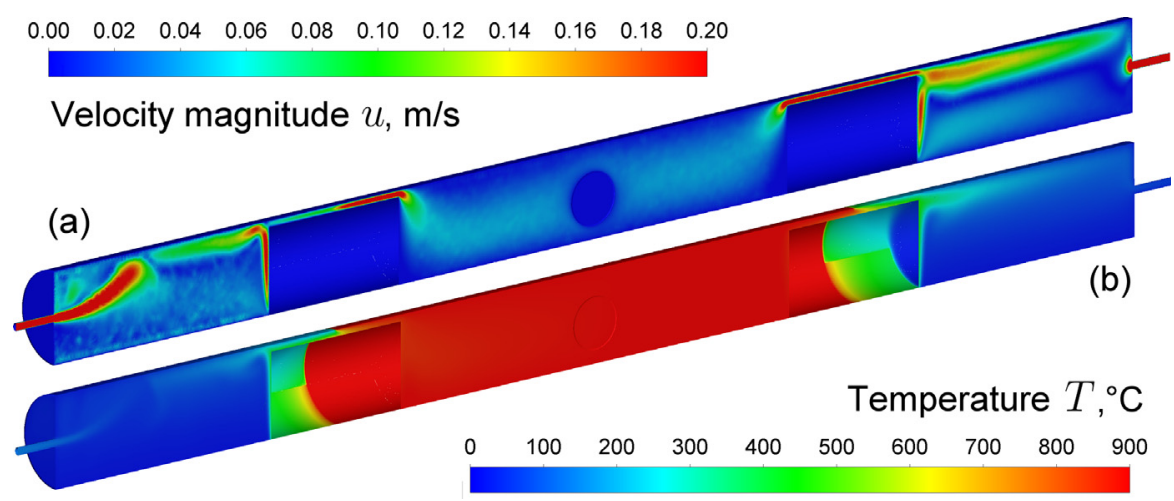

Fig. 2. Velocity (a) and temperature (b) fields obtained from $3 \mathrm{D}$ model calculations. $T_{w}=900{ }^{\circ} \mathrm{C}, P=0.5 \mathrm{bar}, Q_{A}=200 \mathrm{ml} / \mathrm{min}, Q_{E W}=0.5 \mathrm{ml} / \mathrm{min}$.

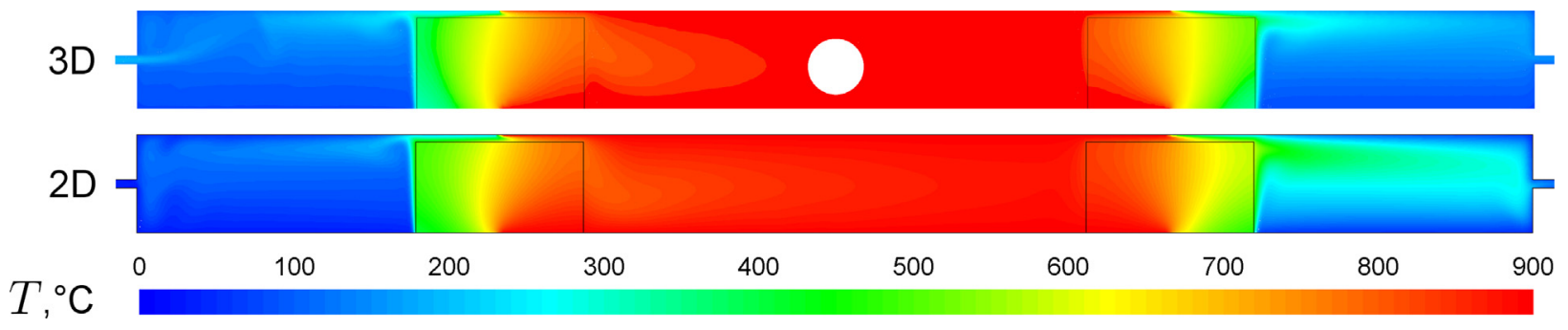

Fig. 3. Temperature field at the tube cross-section for $3 \mathrm{D}$ and $2 \mathrm{D}$ models. $T_{w}=900{ }^{\circ} \mathrm{C}, P=0.5 \mathrm{bar}, Q_{A}=200 \mathrm{ml} / \mathrm{min}, Q_{E W}=0.5 \mathrm{ml} / \mathrm{min}$.

(a)

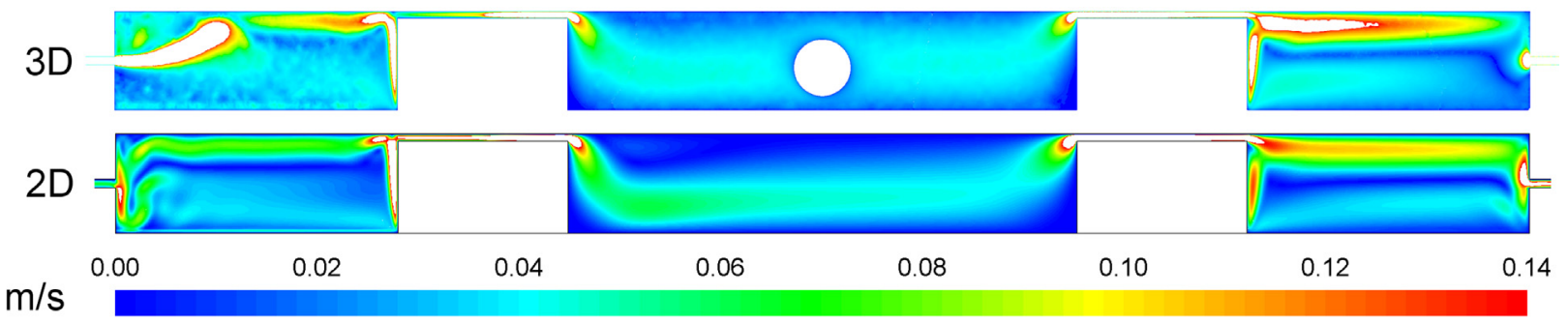

(b)

(1)
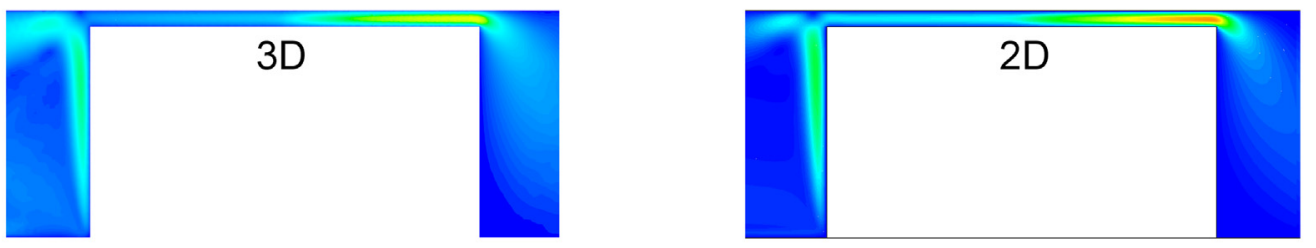

$u, \mathrm{~m} / \mathrm{s}$

0.00

0.05

0.10

0.15

$0.20 \quad 0.25$

0.30

0.35

0.40

0.45

0.50

0.55

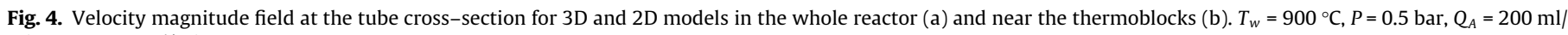
$\min , Q_{E W}=0.5 \mathrm{ml} / \mathrm{min}$.

agreement in the heated section is quite good. Note that in Fig. 4 (a), the scale of velocity magnitude is limited by $0.14 \mathrm{~m} / \mathrm{s}$, so one can observe white spots in those places, where the velocity magnitude exceeds this value. Detailed comparison between velocity fields near the left thermoblock is provided in Fig. 4(b), which shows that the agreement between 2D and 3D models is quite reasonable. Note that the flow in the inlet and outlet sections of the tube is mainly located near the upper wall, while in the heated section it is shifted closer to the lower wall. It happens due density differences in the presence of gravity. Strong gravitational convective flows are also observed near the walls of thermoblocks facing inlet and outlet sections.
The comparison of mole fraction fields for ethylene is shown in Fig. 5. Ethylene is one of the main products of ethanol decomposition, and it is mainly produced in reaction (R1). It first appears at the entrance to the heated section, and its mole fraction reaches high values just near the left thermoblock. The ethylene is consumed in reactions (R35)-(R39), and its concentration decreases along the reactor. This decrease occurs faster in the 3D model in comparison with the 2D model. Nevertheless, the agreement between the two models is rather good.

The mole fractions of 13 selected components averaged over the substrate surface, which is located at the central part of CVD reactor (see Fig. 1), are compared between 3D and 2D models in Fig. 6. 


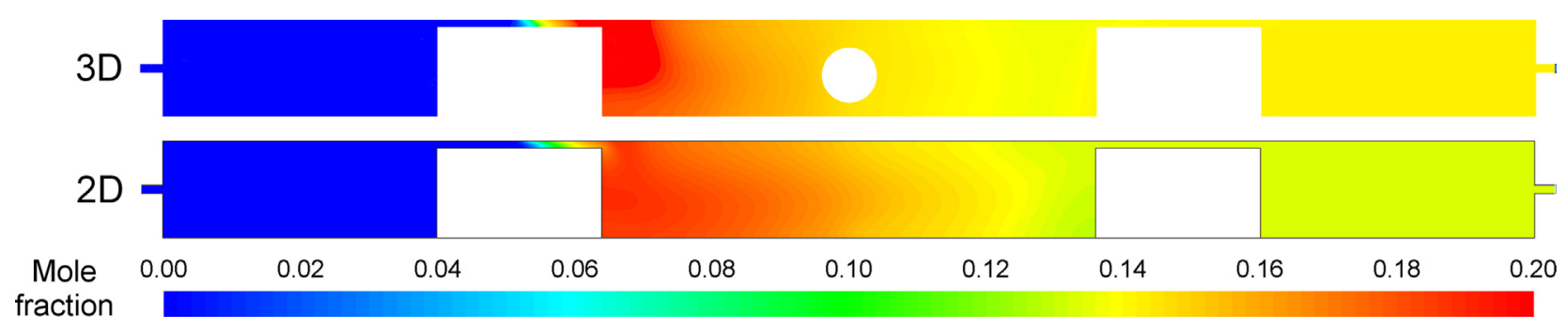

Fig. 5. Mole fraction of $\mathrm{C}_{2} \mathrm{H}_{4}$ at the tube cross-section for $3 \mathrm{D}$ and $2 \mathrm{D}$ models. $T_{w}=900{ }^{\circ} \mathrm{C}, P=0.5 \mathrm{bar}, Q_{A}=200 \mathrm{ml} / \mathrm{min}, Q_{E W}=0.5 \mathrm{ml} / \mathrm{min}$.
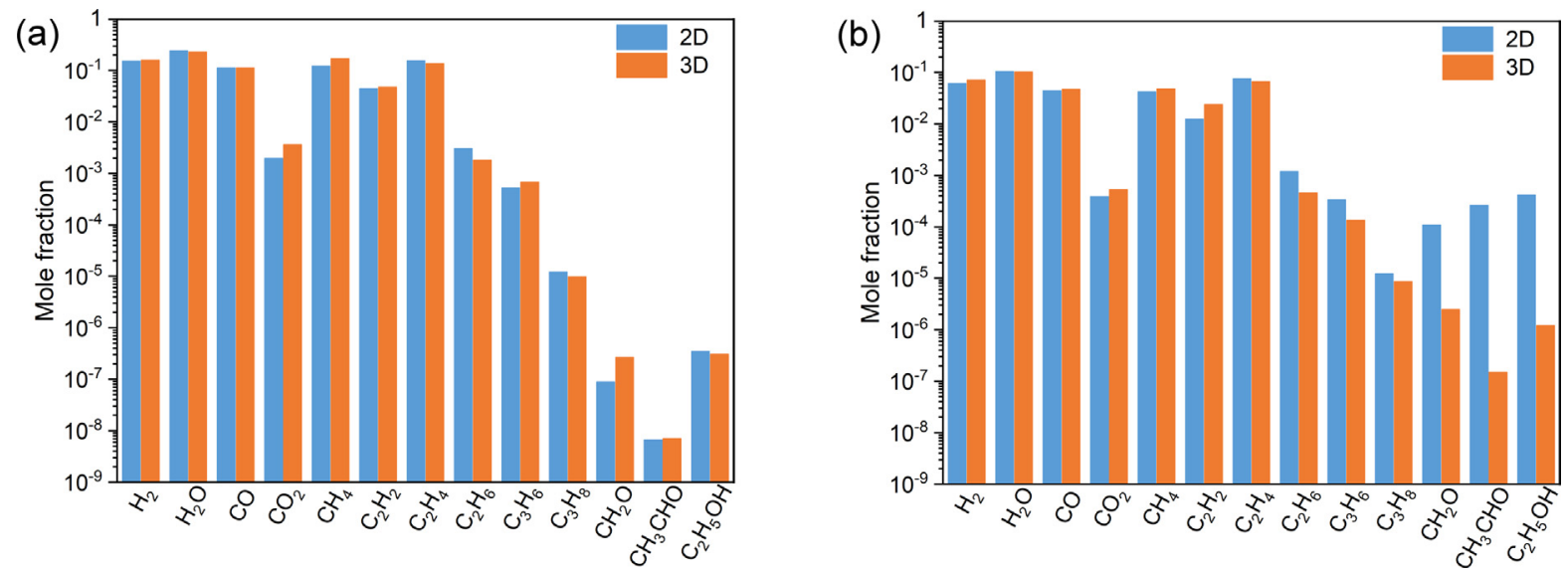

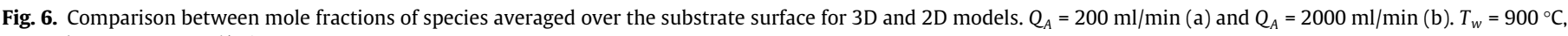
$P=0.5$ bar, $Q_{E W}=0.5 \mathrm{ml} / \mathrm{min}$.

For low argon flow rate of $200 \mathrm{ml} / \mathrm{min}$, the agreement is quite good. The highest differences (2D vs 3D) are observed for $\mathrm{CH}_{2} \mathrm{O}$ (-67\%), $\mathrm{C}_{2} \mathrm{H}_{6}(66 \%)$, and $\mathrm{CO}_{2}(-46 \%)$. When argon flow rate is increased to $2000 \mathrm{ml} / \mathrm{min}$, the agreement becomes worse. The mole fractions of $\mathrm{CH}_{2} \mathrm{O}, \mathrm{CH}_{3} \mathrm{CHO}, \mathrm{C}_{2} \mathrm{H}_{5} \mathrm{OH}$, and, to a lesser extent, $\mathrm{C}_{2} \mathrm{H}_{6}, \mathrm{C}_{3} \mathrm{H}_{6}$ are highly overestimated by the $2 \mathrm{D}$ model. The differences for $\mathrm{C}_{2} \mathrm{H}_{2}$ and $\mathrm{CO}_{2}$ are on the level of $-48 \%$ and $-26 \%$, respectively.

We conclude that the 2D model can be successfully used for calculation of ethanol pyrolysis in the CVD reactor instead of more realistic 3D model. However, it requires the correction of inlet velocity (see Section 2.6) and could be less accurate for high flow rates. In what follows, we will discuss the results obtained on the basis of 2D model (unless otherwise specifically stated).

\section{The influence of temperature}

We have studied the ethanol pyrolysis at different temperatures in the range $500-1500{ }^{\circ} \mathrm{C}$, see Cases $1-11$ in Table 2 . The dependence of temperature averaged over the substrate surface $T_{s}$ on the furnace wall temperature $T_{w}$ is presented in Fig. 7(a). We always observe that $T_{s}<T_{w}$ due to the inflow of gas with a lower temperature through the gap above the left thermoblock, see Fig. 3. However, the comparison between 2D and 3D models at $T_{w}=900$ ${ }^{\circ} \mathrm{C}$ shows that in the latter case the deviation of $T_{s}$ from $T_{w}$ is much smaller. The calculations reveal that this deviation also decreases with decreasing the total volume flow rate, which is controlled by the argon and ethanol/water liquid mixture flow rates. The temperature rise leads to the density decrease and the corresponding increase of velocity at the heated section. It explains the decrease of the residence time with temperature.

The variation of species mole fractions with furnace wall temperature is shown in Fig. 7 (b). The thermal decomposition of ethanol starts when $T_{w}$ exceeds $600{ }^{\circ} \mathrm{C}$. With increasing temperature, we observe the production of ethylene (reaction R1), methane (reactions (R5)-(R7)), hydrogen (reactions (R11)-(R13)), acetaldehyde (reactions (R15), (R16)), and formaldehyde (reactions (R17), (R18)). The evolution of water occurs due to reactions (R1) and (R8)-(R10). The further increase of temperature above $700{ }^{\circ} \mathrm{C}$ leads to the decomposition of acetaldehyde and formaldehyde with the evolution of hydrogen, water, methane, as well as carbon monoxide and dioxide via reaction paths (R19)-(R24) and (R25)-(R34), respectively. The ethylene is decomposed by radicals attack and further converted to acetylene via reactions (R35)-(R42). At higher temperatures $\left(>1000^{\circ} \mathrm{C}\right)$, the production of hydrogen and carbon monoxide increases greatly. The other dominant species under these conditions are acetylene, water, and methane.

The mole fractions calculated at thermodynamic equilibrium are presented in Fig. 7(c). The most striking difference with the reactor operation is observed at low temperatures, where the reaction kinetics is slow, and the residence time is too small for a complete decomposition of ethanol observed at equilibrium conditions. The dominant products at low temperatures are methane, water, carbon monoxide and carbon dioxide, ethylene, and hydrogen. With increasing temperature, the content of hydrogen, carbon monoxide, and acetylene grows, while that of methane, ethylene, and especially carbon dioxide and water reduces. At high temperatures, the reactor operation becomes closer to equilibrium conditions, but the difference in mole fractions of main pyrolysis products (hydrogen, carbon monoxide, and acetylene) still remains significant. The major difference is related to the absence of water and carbon dioxide at equilibrium conditions for temperatures above $1000{ }^{\circ} \mathrm{C}$. The obtained trends are in line with the results of thermodynamic analysis in $[26,48]$.

Fig. 8 presents the profiles of species along the reactor at different temperatures. The cross-sectionally averaged temperature is also shown. It reveals the jumps near the outer walls of ther- 

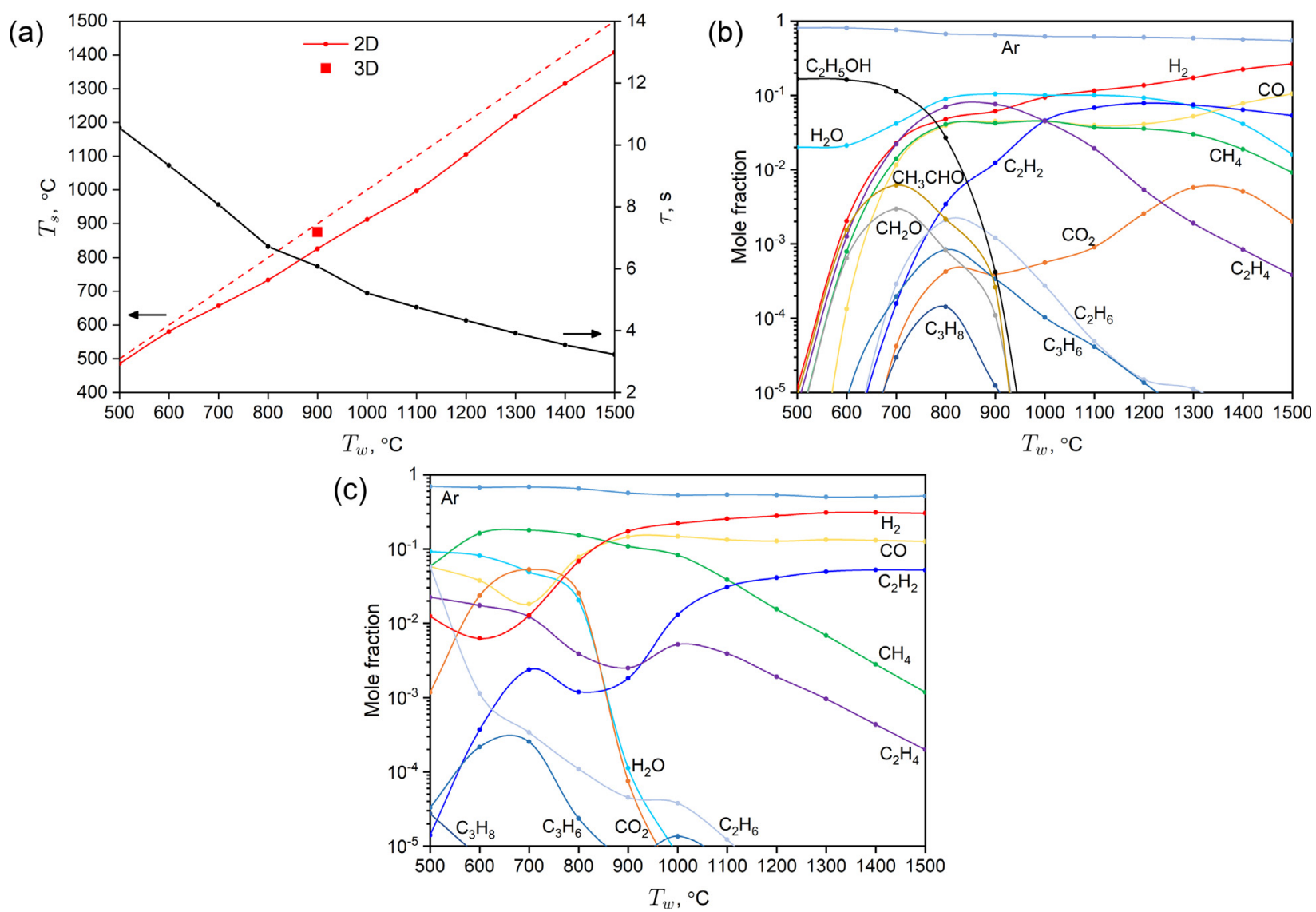

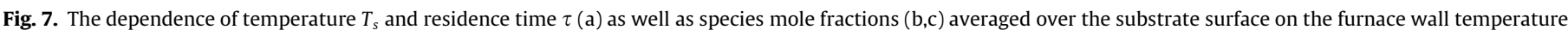
$T_{w}$. The dashed line in (a) corresponds to $T_{s}=T_{w} . P=0.5 \mathrm{bar}, Q_{A}=2000 \mathrm{ml} / \mathrm{min}, Q_{E W}=0.5 \mathrm{ml} / \mathrm{min}$. The thermodynamic equilibrium calculations are shown in (c).

moblocks due to local heating of gas in that areas, see Fig. 3. At 600 ${ }^{\circ} \mathrm{C}$, the mole fraction of ethanol only slightly decreases along the reactor in comparison with the inlet value. The pyrolysis products appear at very low amounts, but their mole fractions increase along the reactor. The increase and subsequent drop of cross-sectionally averaged quantities near the inner wall of right thermoblock are related to the formation of stagnant zone, where the concentration of reaction products increases, see also Fig. 4 . When moving along the reactor to the outlet section, this zone is replaced by a small gap, where the gas flows much faster and the products concentrations are lower. At $900{ }^{\circ} \mathrm{C}$, the decomposition of ethanol starts in the beginning of the heated section above the left thermoblock, but it fully disappears only at the central part of the reactor. The dominant products in this case are water, ethylene, and hydrogen. When temperature is increased up to $1200^{\circ} \mathrm{C}$, the ethanol fully decomposes in the gap above the left thermoblock. The dominant species are hydrogen, water, and acetylene. The strong increase of hydrogen mole fraction along the reactor is observed.

\section{The influence of ethanol/water flow rate}

Let us now analyze how the flow rate of ethanol/water liquid mixture $Q_{E W}$ affects the pyrolysis process. In the calculations, it is varied in the range $0.05-5 \mathrm{ml} / \mathrm{min}$, see Cases $31-38$ in Table 2. The increase of liquid flow rate results in a significant rise of total volume flow rate $Q$ in the gas phase. Fig. 9 (a) shows that it leads to the decrease of residence time as well as the temperature of substrate surface $T_{s}$. The latter effect is explained by the higher inflow of gas with a lower temperature into the heated section. At the highest flow rate considered $(5 \mathrm{ml} / \mathrm{min})$, the averaged temperature of the substrate drops to $658^{\circ} \mathrm{C}$ when the wall temperature is kept at $900{ }^{\circ} \mathrm{C}$.

The dependence of species mole fractions on the ethanol/water mixture flow rate $Q_{E W}$ is presented in Fig. 9(b). One can see that for flow rates higher than $0.5 \mathrm{ml} / \mathrm{min}$, the ethanol is not fully decomposed in the reactor volume, and its mole fraction increases with increasing $Q_{E W}$ reaching a plateau of about 0.2 for $Q_{E W}>3$ $\mathrm{ml} / \mathrm{min}$. The concentrations of major pyrolysis products (water, ethylene, hydrogen, carbon monoxide, methane, acetylene) increase with $Q_{E W}$ at low flow rates, but attain almost constant values for flow rates higher then $1 \mathrm{ml} / \mathrm{min}$. The rest of species demonstrate a similar trend.

The profiles of temperature and species along the reactor are shown in Fig. 10. The presence of ethanol in the reactor volume as well as the temperature decrease for high flow rate of 3 $\mathrm{ml} / \mathrm{min}$ (Fig. 10(b)) in comparison with the low flow rate of $0.25 \mathrm{ml} / \mathrm{min}$ (Fig. 10(a)) are clearly seen. Note that with lowering temperature, the ethanol decomposition rate and, correspondingly, the production rate of pyrolysis products becomes lower. It explains a slight decrease of hydrogen, methane, and acetylene mole fractions with increasing $Q_{E W}$, see Fig. 9(b). The profiles of ethanol, water, and ethylene are strongly correlated in Fig. 10(b), which confirms the major role of reaction (R1) in the unimolecular ethanol decomposition. The drop of cross-sectionally averaged ethanol mole fraction and the rise of products mole fractions near the inner walls of thermoblocks are caused by the formation of stagnant zones with increased temperature and, consequently, reactions rate. 

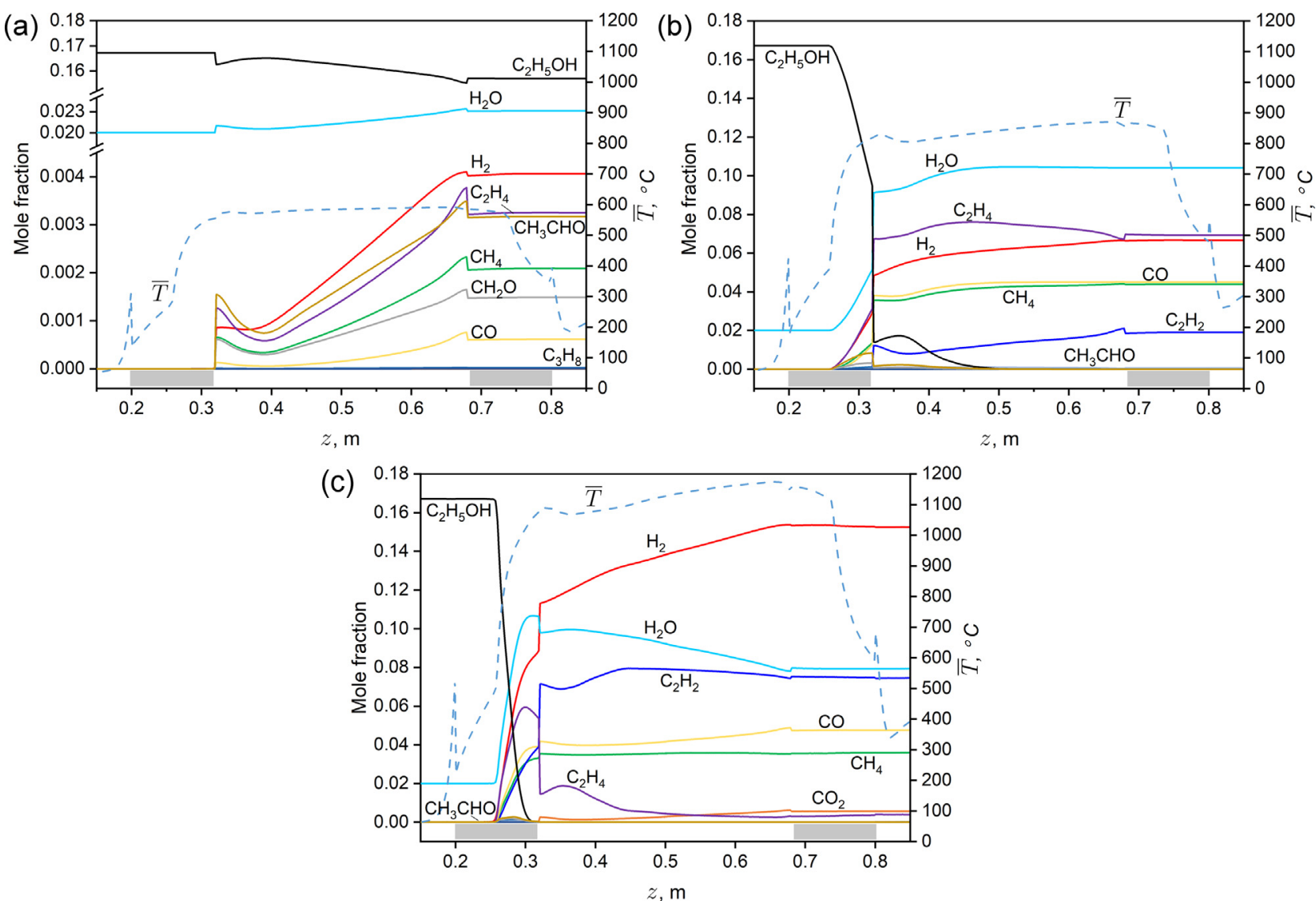

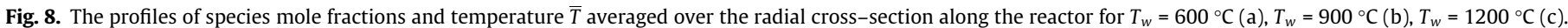
$P=0.5$ bar, $Q_{A}=2000 \mathrm{ml} / \mathrm{min}, Q_{E W}=0.5 \mathrm{ml} / \mathrm{min}$. The grey rectangles near the horizontal axis show the position of thermoblocks.

(a)

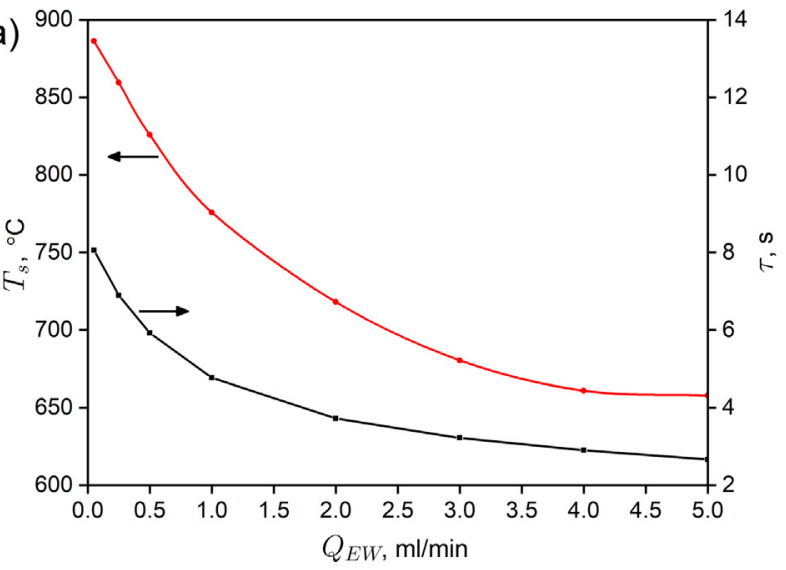

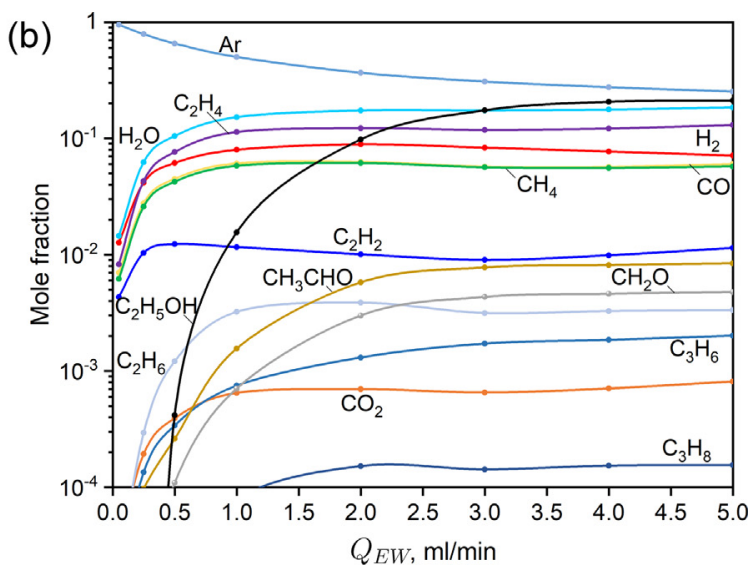

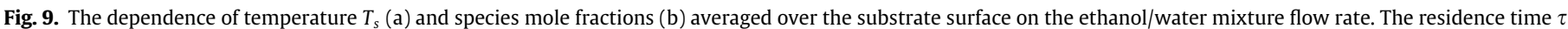
is also shown in (a). $T_{w}=900{ }^{\circ} \mathrm{C}, P=0.5 \mathrm{bar}, Q_{A}=2000 \mathrm{ml} / \mathrm{min}$.

\section{The influence of argon flow rate}

In this study, we have varied the argon flow rate in the range 10-2000 $\mathrm{ml} / \mathrm{min}$, see Cases $20-30$ in Table 2. Fig. 11(a) shows that the increase of $Q_{A}$ leads to the decrease of residence time and temperature over the substrate surface. As expected, the mole fraction of argon becomes larger, while the mole fractions of other species become smaller with increasing $Q_{A}$, see Fig. 11(b). Lower residence times at higher values of argon flow rate result in the rise of acetaldehyde and formaldehyde concentrations. The latter are produced in reactions of ethanol with radicals (R6), (R7), (R9), (R10),
(R12), (R13) followed by decomposition reactions (R15)-(R18). With increasing argon flow rate, the presence of ethanol in the reactor is observed as well since it does not have enough time to decompose fully due to smaller residence time.

\section{The influence of pressure}

Finally, let us consider the impact of pressure on the ethanol decomposition. The considered range of pressures is $0.1-1$ bar. The corresponding parameters are listed in Table 2, see Cases 12-19. It 
(a)

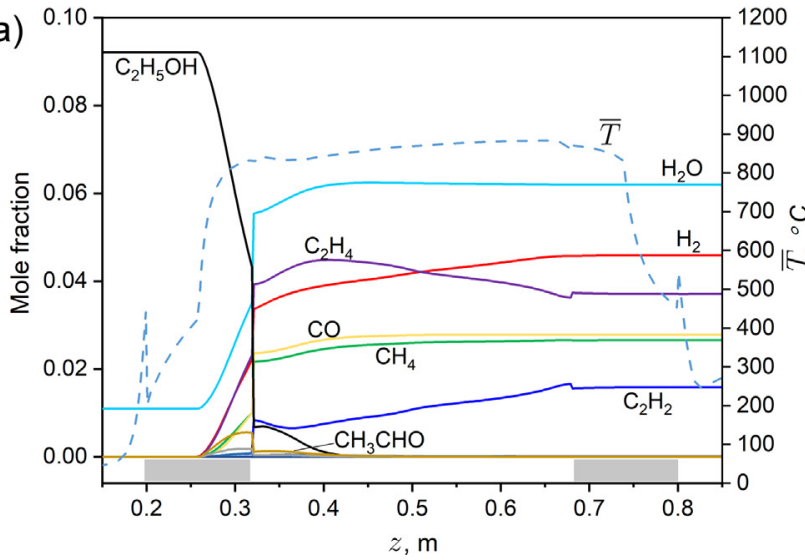

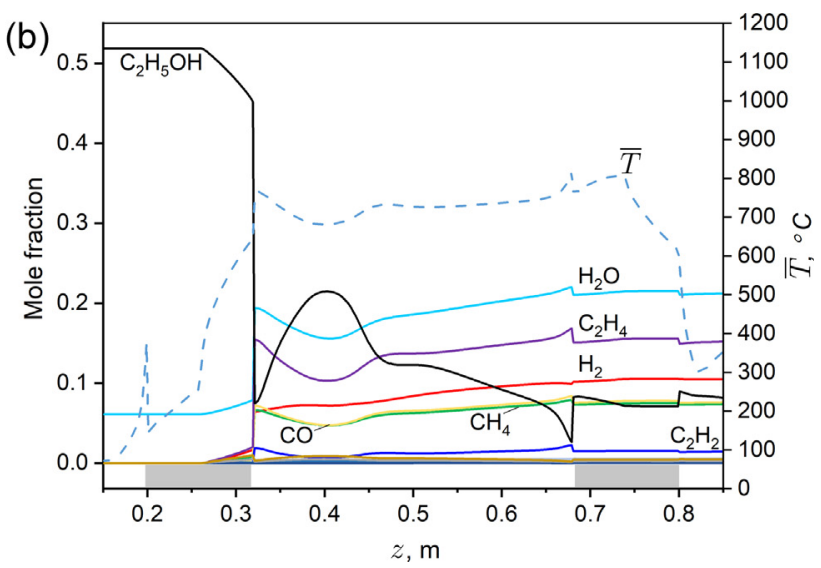

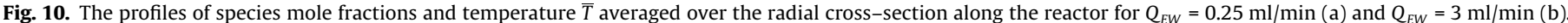
$T_{w}=900{ }^{\circ} \mathrm{C}, P=0.5 \mathrm{bar}, Q_{A}=2000 \mathrm{ml} / \mathrm{min}$. The grey rectangles near the horizontal axis show the position of thermoblocks.
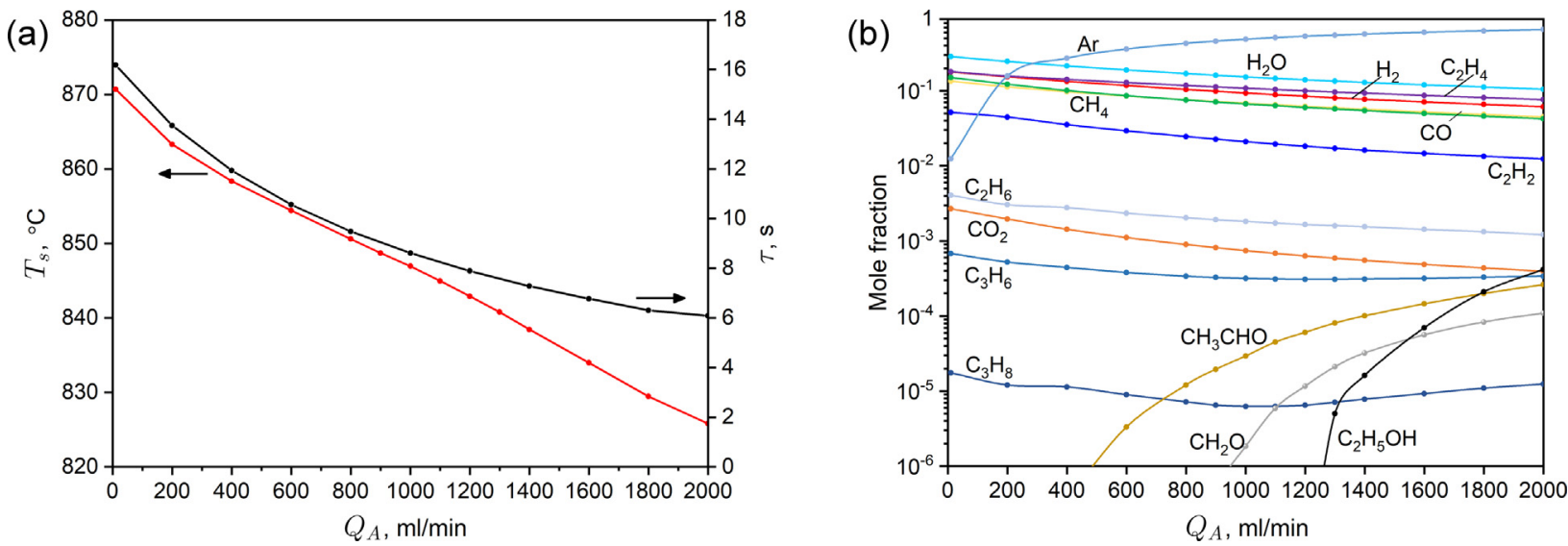

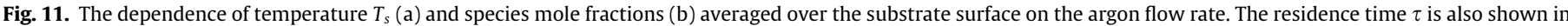
(a). $T_{w}=900^{\circ} \mathrm{C}, P=0.5 \mathrm{bar}, Q_{E W}=0.5 \mathrm{ml} / \mathrm{min}$.

follows from (8) that the pressure increase leads to the decrease of total volume flow rate $Q$. Thus, the residence time becomes larger with the growth of working pressure, Fig. 12 (a). However, the mass flow rate of argon and the total mass flow rate increase with pressure since the density of argon $\rho_{A}$ in (7) is proportional to it. One can also observe a slight decrease of temperature over the substrate surface with increasing pressure. The mole fractions of pyrolysis products shown in Fig. 12(b) demonstrate a decrease with pressure mainly due to the increase of argon to ethanol mole fractions ratio in the inlet mixture, see the last column in Table 2. At the same time, the analysis of products molar concentrations $\left(\mathrm{mol} / \mathrm{m}^{3}\right.$ ) shows that they increase with pressure due to larger residence times (not presented
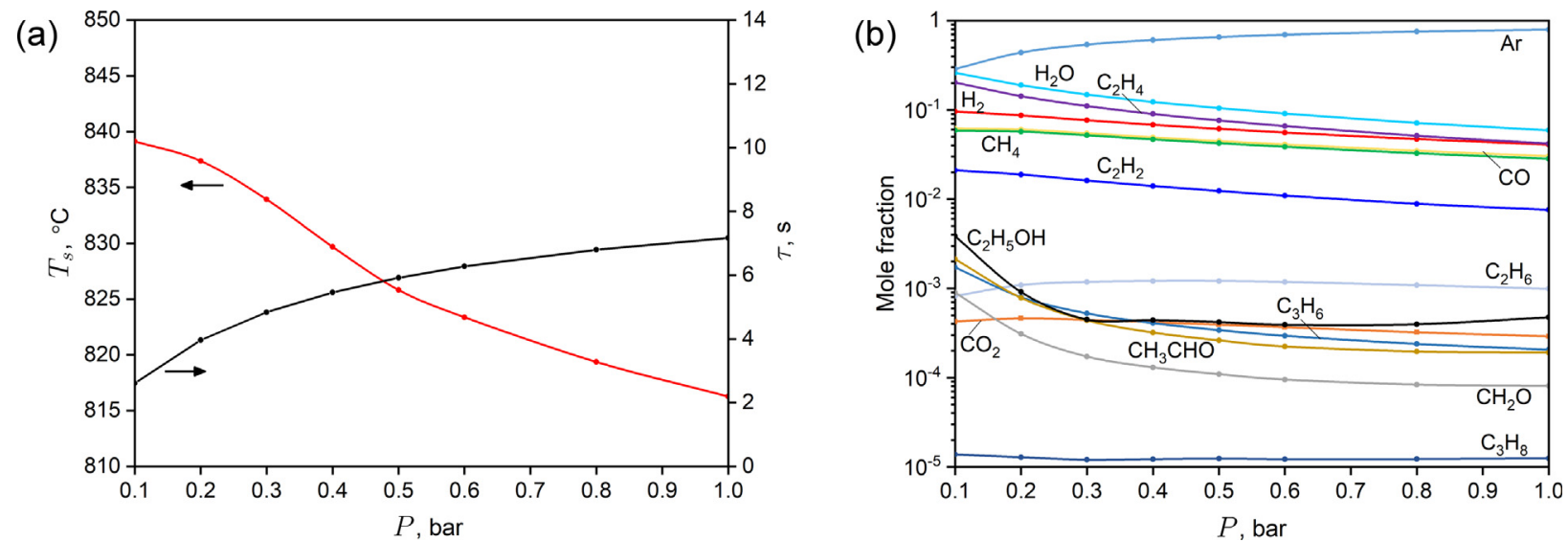

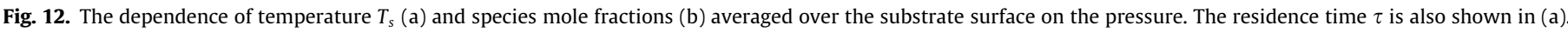
$T_{w}=900{ }^{\circ} \mathrm{C}, Q_{A}=2000 \mathrm{ml} / \mathrm{min}, Q_{E W}=0.5 \mathrm{ml} / \mathrm{min}$. 
here). Higher concentrations of ethanol, acetaldehyde, and formaldehyde at lower pressures are explained by smaller residence times, see Fig. 12.

\section{Conclusion}

In this work, we have performed computational modelling of ethanol pyrolysis in a commercial CVD reactor, which has the form of a cylindrical tube with the heated section. The inlet gas flow is produced by evaporating azeotrope ethanol/water mixture followed by mixing it with the inert gas (argon). Previously, this reactor was employed for growing carbon layers on alumina substrates (membranes).

The modelling is performed with the help of ANSYS Fluent 17 software package in 3D and 2D statements using Marinov mechanism. The transport of heat and species by convection and diffusion as well as the presence of gravity are taken into account. The control parameters are varied in the following ranges: temperature 500-1500 ${ }^{\circ} \mathrm{C}$, pressure $0.1-1 \mathrm{bar}$, argon flow rate $10-2000$ $\mathrm{ml} / \mathrm{min}$, and ethanol/water liquid flow rate $0.05-5 \mathrm{ml} / \mathrm{min}$. The obtained results can be summarized as follows:

1. Consideration of a real reactor geometry with the heated section separated from the inlet and outlet sections by thermoblocks leads to large variations of temperature along the reactor and requires taking into account the temperature dependencies of viscosity, thermal conductivity, and species diffusion coefficients as well as radiative heat transfer on the boundaries.

2. The meaningful comparison of results between a real 3D tubular reactor and a 2D plane channel requires the correction of inlet velocity, which should be an order of magnitude smaller in the 2D statement. A good agreement is found between species mole fractions at the substrate position for 3D and 2D calculations at low volume flow rates. For high flow rates, the main deviations are observed for ethanol, acetaldehyde, and formaldehyde.

3. The temperature at the substrate in the reactor center is always lower than the wall temperature, and this deviation becomes larger with increasing ethanol/water and argon volume flow rates as well as pressure due to inflow of a colder gas from the inlet section. The residence time decreases with wall temperature and volume flow rate, but increases with pressure.

4. In the considered range of flow rates, the ethanol decomposition starts at around $600{ }^{\circ} \mathrm{C}$. At moderate temperatures around $900{ }^{\circ} \mathrm{C}$, the main pyrolysis products are water, ethylene, hydrogen, carbon monoxide, and methane. The further temperature rise increases the mole fractions of hydrogen, acetylene, and carbon monoxide, while the water and methane mole fractions are decreased.

5. With increasing ethanol/water volume flow rate, the mole fractions of pyrolysis products increase reaching almost constant values for flow rates higher than $1 \mathrm{ml} / \mathrm{min}$. Under such conditions, the ethanol is not fully decomposed at the reactor volume, and its mole fraction reaches a constant value for flow rates higher then $3 \mathrm{ml} / \mathrm{min}$.

6. The rise of argon flow rate leads to the decrease of pyrolysis products mole fractions due decrease of residence time. The latter increases with pressure, which causes the rise of products molar concentrations.

7. Comparison of reactor performance with thermodynamic equilibrium calculations shows significant differences, especially for low temperature regimes.

The obtained results can be employed for simulating and analyzing pyrolysis processes in realistic CVD reactors with complex geometry. They also provide the basis for the development of coupled gas phase and surface reaction model of carbon layer growth on alumina substrates.

\section{Declaration of Competing Interest}

The authors declared that there is no conflict of interest.

\section{Acknowledgement}

This work is supported the Russian Foundation for Basic Research, Project 18-29-19078.

\section{Appendix A. Supplementary material}

Supplementary data associated with this article can be found, in the online version, at https://doi.org/10.1016/j.ijheatmasstransfer. 2019.118764.

\section{References}

[1] Y. Xu, X.T. Yan, Chemical Vapour Deposition - An Integrated Engineering Design for Advanced Materials, Springer, London, 2010.

[2] Chemical vapour deposition: precursors, processes and applications, in: A.C. Jones, M.L. Hitchman (Eds.). RSC Publishing, Cambridge, UK 2009.

[3] K.L. Choy, Chemical vapour deposition of coatings, Prog. Mater. Sci. 48 (2) (2003) 57-170.

[4] A. Oberlin, Pyrocarbons, Carbon 40 (1) (2002) 7-24.

[5] P. Delhaes, Chemical vapor deposition and infiltration processes of carbon materials, Carbon 40 (5) (2002) 641-657.

[6] K.J. Hüttinger, CVD in hot wall reactors - the interaction between homogeneous gas-phase and heterogeneous surface reactions, Chem. Vapor. Dep. 4 (1998) 151-158.

[7] K. Norinaga, O. Deutschmann, K.J. Hüttinger, Analysis of gas-phase compounds in chemical vapor deposition of carbon from light hydrocarbons, Carbon 44 (9) (2006) 1790-1800.

[8] K. Norinaga, O. Deutschmann, Detailed kinetic modelling of gas-phase reactions in the chemical vapor deposition of carbon from light hydrocarbons, Ind. Eng. Chem. Res. 46 (11) (2007) 3547-3557.

[9] K. Norinaga, V.M. Janardhanan, O. Deutschmann, Detailed chemical kinetic modelling of pyrolysis of ethylene, acetylene, and propylene at 1073-1373 K with a plug-flow reactor model, Int. J. Chem. Kinet. 40 (4) (2008) 199-208.

[10] A. Li, K. Norinaga, W. Zhang, O. Deutschmann, Modelling and simulation of materials synthesis: chemical vapor deposition and infiltration of pyrolytic carbon, Comp. Sci. Techn. 68 (5) (2008) 1097-1104.

[11] K. Yu, C.C. Hayman, S. Manjunath, W. Fan, I.T. Martin, H.B. Martin, R.M. Sankaran, A combibed CFD modelling and experimental study of pyrolytic carbon deposition, Diamond Related Mater. 70 (2016) 173-178.

[12] P. McAllister, E.E. Wolf, Simulation of a multiple substrate reactor for chemical vapor infiltration of pyrolytic carbon within carbon-carbon composities, AIChE J. 39 (7) (1993) 1196-1209.

[13] P. Mishra, N. Verma, A CFD study on a vertical chemical vapor deposition reactor for growing carbon nanofibers, Chem. Eng. Res. Des. 90 (12) (2012) 2293-2301.

[14] J. Ibrahim, S. Paolucci, The modelling of realistic chemical vapor deposition/ infiltration reactors, Int. J. Numer. Method. Fluids 64 (5) (2010) 473-516.

[15] A. Li, S. Zhang, B. Reznik, S. Lichtenberg, O. Deutschmann, Sythesis of pyrolytic carbon composites using ethanol as a precursor, Ind. Eng. Chem. Res. 49 (21) (2010) 10421-10427.

[16] G. Rotzoll, High-temperature pyrolysis of ethanol, J. Anal. Apll. Pyrol. 9 (1) (1985) 43-52.

[17] J. Li, A. Kazakov, F.L. Dryer, Ethanol pyrolysis experiments in a variable pressure flow reactor, Int. J. Chem. Kinet. 33 (12) (2001) 859-867.

[18] J. Li, A. Kazakov, F.L. Dryer, Experimental and numerical studies of ethanol decomposition reactions, J. Phys. Chem. A 108 (38) (2004) 7671-7680.

[19] N.M. Marinov, A detailed chemical kinetic model for high temperature ethanol oxidation, Int. J. Chem. Kinet. 31 (3) (1999), 1823-220.

[20] J. Keicherer, C. Bänsch, T. Bentz, M. Olzmann, Pyrolysis of ethanol: a shocktube/TOF-MS and modeling study, Proc. Comb. Inst. 35 (1) (2015) 465-472.

[21] A. Li, S. Zhang, B. Reznik, S. Lichtenberg, G. Schoch, O. Deutschmann, Chemistry and kinetics of chemical vapor deposition of pyrolytic carbon from ethanol, Proc. Comb. Inst. 33 (2) (2011) 1843-1850.

[22] C. Esarte, M. Peg, M.P. Ruiz, A. Millera, R. Bilbao, M.U. Alzueta, Pyrolysis of ethanol: gas and soot products formed, Ind. Eng. Chem. Res. 50 (8) (2011) $4412-4419$.

[23] C. Esarte, A. Millera, R. Bilbao, M.U. Alzueta, Gas and soot product formed in the pyrolysis of acetylene-ethanol blends under flow reactor conditions, Fuel Process. Techn. 90 (4) (2009) 496-503. 
[24] G.K. Gupta, A.M. Dean, K. Ahn, R.J. Gorte, Comparison of conversion and deposit formation of ethanol and butane under SOFC conditions, J. Power Sources 158 (1) (2006) 497-503.

[25] S. Roychowdhury, T. Sundararajan, Sarit Kumar Das, Conjugate heat transfer studies on steam reforming of ethanol in micro-channel systems, Int. J. Heat Mass Trans. 139 (2019) 660-674.

[26] A.L. Da Silva, C.F. Malfatti, I.L. Muüller, Thermodynamic analysis of ethanol steam reforming using Gibbs energy minimization method: a detailed study of the conditions of carbon deposition, Int. J. Hydrogen Energy 34 (10) (2009) 4321-4330.

[27] G. Vourliotakis, G. Skevis, M.A. Founti, Detailed kinetic modelling of noncatalytic ethanol reforming for SOFC applications, Int. J. Hydr. Energy 34 (18) (2009) 7626-7637.

[28] S. Maruyama, R. Kojima, Y. Miyauchi, S. Chiashi, M. Kohno, Low-temperature synthesis of high-purity single-walled carbon nanotubes from alcohol, Chem. Phys. Lett. 360 (3-4) (2002) 229-234.

[29] I.I. Bobrinetskii, V.K. Nevolin, M.M. Simunin, Production of carbon nanotubes by catalytic gas-phase pyrolysis of ethanol, Theor. Found. Chem. Eng. 41 (5) (2007) 639-643.

[30] G. Faggio, A. Capasso, G. Messina, S. Santangelo, Th. Dikonimos, S. Gagliardi, R. Giorgi, V. Morandi, L. Ortolani, N. Lisi, High-temperature growth of graphene films on copper foils by ethanol chemical vapor deposition, J. Phys. Chem. C. 117 (41) (2013) 21569-21576.

[31] D. Mattia, H. Leese, K.P. Lee, Carbon nanotube membranes - from flow enhancement to permeability, J. Membr. Sci. 475 (1) (2015) 266-272.

[32] M. Alsawat, T. Altalhi, T. Kumeria, A. Santos, D. Losic, Carbon nanotubenanoporous anodic alumina composite membranes with controllable inner diameters and surface chemistry: influence on molecular transport and chemical selectivity, Carbon 93 (2015) 681-692.

[33] V.S. Solodovnichenko, D.V. Lebedev, V.V. Bykanova, A.V. Shiverskiy, M.M. Simunin, V.A. Parfenov, I.I. Ryzhkov, Carbon coated alumina nanofiber membrane for selective ion transport, Adv. Eng. Mater. 19 (11) (2017) 1700244.

[34] V.S. Solodovnichenko, M.M. Simunin, D.V. Lebedev, A.S. Voronin, A.V. Emelianov, Y.L. Mikhlin, V.A. Parfenov, I.I. Ryzhkov, Coupled thermal analysis of carbon layers deposited on alumina nanofibers, Thermochim. Acta 675 (2019) 164-171.
[35] I.I. Ryzhkov, D.V. Lebedev, V.S. Solodovnichenko, A.V. Minakov, M.M. Simunin, On the origin of membrane potential in membranes with polarizable nanopores, J. Membr. Sci. 549 (1) (2018) 616-630.

[36] D.V. Lebedev, V.S. Solodovnichenko, M.M. Simunin, I.I. Ryzhkov, Effect of electric field on ion transport in nanoporous membranes with conductive surface, Petrol. Chem. 58 (6) (2018) 474-481.

[37] W.K. Cho, D.H. Choi, M.U. Kim, Optimization of inlet concentration profile for uniform deposition in a cylindrical chemical vapor deposition chamber, Int. J. Heat Mass Trans. 42 (6) (1999) 1141-1146.

[38] I.K. Kim, W.S. Kim, Theoretical analysis of wafer temperature dynamics in a low pressure chemical vapor deposition reactor, Int. J. Heat. Mass Trans. 42 (22) (1999) 4131-4142.

[39] G. Luo, S.P. Vanka, N. Glumac, Fluid flow and transport processes in a large area atmospheric pressure stagnation flow CVD reactor for deposition of thin films, Int. J. Heat Mass Trans. 47 (23) (2004) 4979-4994.

[40] I. Kunadiana, R. Andrews, M.P. Mengüuc, D. Qiana, Multiwalled carbon nanotube deposition profiles within a CVD reactor: An experimental study, Chem. Eng. Sci. 64 (7) (2009) 1503-1510.

41] <https://combustion.llnl.gov/archived-mechanisms/ethanol>.

[42] CRC Handbook of Chemistry and Physics, 8th ed., CRC Press, 2003, 2003-2004.

[43] NIST Chemistry WebBook, <https://webbook.nist.gov/chemistry/>.

44] V.J.H. Lienhard, J.H. Lienhard IV, A heat transfer textbook, fourth ed., Dover Publications, New York, 2011.

[45] Z. Živcová, E. Gregorová, W. Pabst, D.S. Smith, A. Michot, C. Poulier, Therma conductivity of porous alumina ceramics prepared using starch as a poreforming agent, J. Europ. Ceram. Soc. 29 (3) (2009) 347-353.

[46] Bauer W., Moldenhauer A., Platzer A. Emissivities of ceramic materials for high temperature processes. Proc. SPIE 5880, Optical Diagnostics, 58800W. https://doi.org/10.1117/12.624512.

[47] J. Park, R.S. Zhu, M.C. Lin, Thermal decomposition of ethanol. I. Ab Initio molecular orbital/ Rice-Ramsperger-Kassel-Marcus prediction of rate constant and product branching ratios, J. Chem. Phys. 117 (2002) 3224-3231.

[48] G. Rabenstein, V. Hacker, Hydrogen for fuel cells from ethanol to steamreforming, partial oxidation and combined auto-thermal reforming: a thermodynamic analysis, J. Power Sources 185 (2) (2008) 1293-1304. 